Faculdade de Zootecnia e Engenharia de Al iment os

\title{
EFEITO FRACIONAMENTO DE CÁLCIO E GRANULOMETRIA DE CALCÁRIO SOBRE O DESEMPENHO E QUALIDADE DE OVOS DE POEDEIRAS COMERCIAIS BRANCAS
}

\section{Diogo Tsuyoshi lto}

Dissertação de Mestrado depositada na Seção de Pós-Graduação da Faculdade de Zootecnia e Engenharia de Alimentos da USP, como parte dos requisitos para a obtenção do Título de Mestre em Zootecnia, na área de Concentração: Qualidade e Produtividade Animal.

Orientador: Prof.Dr. Douglas Emygdio de Faria 
FICHA CATALOGRÁFICA

preparada pela

Biblioteca da Faculdade de Zootecnia e Engenharia de Alimentos da Universidade de São Paulo

Ito, Diogo Tsuyoshi

I89e Efeito do fracionamento de cálcio e granulometria de calcário sobre o desempenho e qualidade de ovos de poedeiras comerciais brancas / Diogo Tsuyoshi Ito - Pirassununga, 2002.

$63 \mathrm{p}$.

Dissertação (Mestrado) -- Faculdade de Zootecnia e Engenharia de Alimentos - Universidade de São Paulo. Departamento de Zootecnia.

Área de concentração: Qualidade e Produtividade Animal.

Orientador: Prof. Dr. Douglas Emygdio de Faria.

Unitermos: 1. Poedeiras 2. Cálcio 3. Ovos, qualidade de casca I. Título. 
"O pensamento faz a grandeza do homem"

(Pascal)

"Quem mais sabe, mais duvida"

(Pio III)

"A inteligência é o farol que nos guia, mas é a vontade que nos faz caminhar"

(Anônimo) 


\section{AGRADECIMENTOS}

Desenvolver um trabalho de pesquisa requer alguns aspectos que podemos aprender através da experiência dos demais ou por vivência própria. Mas é explícita a necessidade de que estes estudos devem ser conduzidos em conjunto para que através da troca de informações e formação de idéias seja possível chegar a novos pontos de vista, revisar conceitos, etc. Definitivamente estamos na era da informação. $O$ volume de informações é cada vez maior e o tempo para assimilar e raciocinar cada vez menor. Dividir torna-se uma necessidade para que estes conhecimentos adquiridos sejam multiplicados.

Nesse sentido, sinceramente agradeço:

- Prof. Dr. Douglas Emygdio de Faria, por seus conhecimentos, caráter e companheirismo em prol da ciência e formação profissional de seus orientados. No meu caso, desde a graduação. Um exemplo a ser seguido. Organização. Idéias. Crescimento.

- Prof. Dr. Ricardo de Albuquerque, que mesmo atuando como prefeito do Campus Administrativo de Pirassununga, me auxiliou na condução deste trabalho conjunto, seja disponibilizando as estruturas do Campus para diversas atividades, seja através dos conselhos durante a condução do experimento. Serenidade. Prontidão. Capacitação.

- Faculdade de Zootecnia e Engenharia de Alimentos, através da Comissão de Pós-Graduação, pelas condições propícias para o estudo, condução e conclusão deste trabalho de pesquisa. Em constante mudança desde os tempos da graduação. Mudança. Ampliação. Divulgação.

- Ministrantes das disciplinas cursadas pela bagagem de conhecimento oferecida. Professores Doutores Douglas Emygdio de Faria, Valdomiro Shigueru Miyada, Antônio Augusto Mendes Maia, Antônio Lencioni Titto, Holmer Savastano Junior, Paulo José do Amaral Sobral, João Alberto Negrão, Rogério Lacaz Ruiz. Conhecimento. Orientação.

- Prof. Dra. Catarina Abdalla Gomide, que através do laboratório de análises bromatológicas, possibilitou a análise laboratorial dos calcários. Paciência.

- Granja Saito S.A., na figura de toda a Diretoria e seus colaboradores, pela oportunidade para pesquisar, visando sempre a qualidade do alimento produzido para o consumidor. História.

- Nelson Haga, companheiro na assessoria técnica da Saito, por desdobrar-se em vários durante as minhas ausências. Eficiência. 
- Nutron Alimentos Ltda pelo apoio material, intelectual e moral. Vanguarda.

- Silene Regina Polli, chefe do departamento técnico da Nutron Alimentos Ltda. e Ronnie Dari, por proporcionarem acesso a fontes bibliográficas relevantes. Empolgação.

- Regina Bacci, chefe do laboratório de análises bromatológicas da Nutron Alimentos Ltda., graças ao esforço próprio e de sua equipe foi possível enriquecer este trabalho com informações que servirão de referência para diversos pesquisadores. Seriedade.

- Ricardo Ito, coordenador de serviços em avicultura de postura da Nutron Alimentos Ltda. e Prof. Dr. Antônio Mário Penz Júnior, Diretor Técnico, por acreditarem nesta linha de pesquisa. Profissional.

- Sr. José Américo, Mineradora Cinderela, pelo entusiasmo em colaborar para a ciência através da doação do calcário calcítico. Entusiasta.

- Bolsistas de iniciação científica, Elizabete Aiko Kuwano e Samir Henrique Siqueira, pelo auxílio total e inegável durante toda a condução do experimento. Graças à competência e trabalho árduo de ambos, durante todo este período, vários serão os frutos a serem colhidos. Interesse. Competência. Alegria.

- Entidades, FAPESP e CNPq, por financiarem as bolsas de iniciação científica dos alunos de graduação. Oportunidade.

- Cláudio, Fábio e "China", responsáveis pelo setor de Avicultura, o profissionalismo foi considerado durante a escolha do local para condução desta pesquisa. Auxílio. Confiança. Risos.

- Bibliotecários da FZEA, FMVZ, FCF, ESALQ por recolocarem em seus devidos lugares os diversos periódicos que pesquisei. Corrigir imperfeições de redação. Agradeço a existência da fotocópia e scanner.

- Carlos Utiyama e Liliana Oeting, informações diversas, dicas, análises estatísticas, banquetes em Piracicaba. Pesquisadores de futuro. Casal modelo. Amizade.

- Às aves. Sacrifício.

- Et al., colegas de pós-graduação e graduação, companheiros de repúblicas que me auxiliaram a enriquecer a ciência. Convívio.

- Família, familiares e amigos. Tudo.

Passaram-se breves 3 anos de pesquisa, manter relacionamento com instituições privadas e públicas é extremamente interessante. Dinâmico. $\mathrm{Na}$ escola sempre ouvi: "A prática é diferente da teoria". Mas até que ponto "a prática difere da teoria por não segui-la?" 


\section{SUMÁRIO}

Página

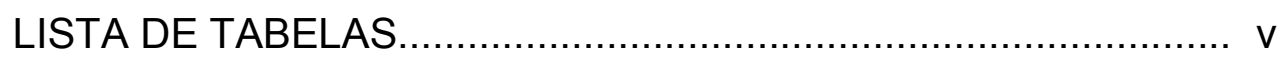

LISTA DE ABREVIATURAS.................................................... vii

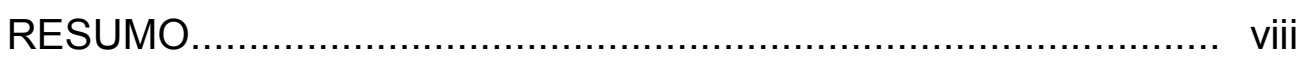

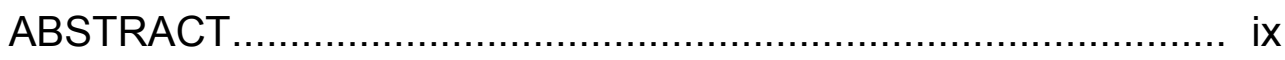

1. INTRODUÇÃO

2. REVISÃO DE LITERATURA............................................... 03

2.1. Formação da casca e fracionamento de cálcio................... 03

2.2. Granulometria e solubilidade do calcário............................. 08

3. MATERIAL E MÉTODOS................................................ 12

3.1. Local e período........................................................... 12

3.2. Animais experimentais e delineamento experimental........ 12

3.3. Instalações e equipamentos............................................ 13

3.4. Rações experimentais.................................................... 14

3.5. Características avaliadas............................................. 15

3.5.1. Características de desempenho zootécnico............... 15

3.5.2. Características de qualidade interna dos ovos........... 16

3.5.3. Características de qualidade externa dos ovos........... 16

3.5.4. Solubilidade das fontes de cálcio............................. 17

3.6. Análise estatística........................................................... 18

4. RESULTADOS E DISCUSSÃO............................................. 19

4.1. Características de desempenho zootécnico....................... 19

4.2. Características de qualidade interna dos ovos................... 32

4.3. Características de qualidade externa dos ovos.................. 45

4.4. Solubilidade dos calcários................................................. 54

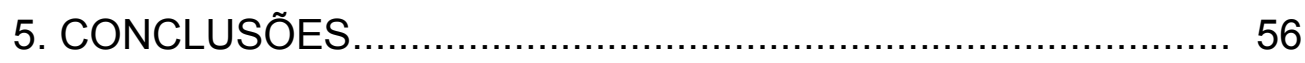

6. REFERÊNCIAS BIBLIOGRÁFICAS........................................ 57 


\section{LISTA DE TABELAS}

TABELA

Página

1. Relação dos tratamentos experimentais...................................... 13

2. Níveis nutricionais e composição das rações experimentais.................... 14

3. Valores de solubilidade (\%) e nível de cálcio (\%) obtidos para diferentes granulometrias de calcário.

4. Valores de produção de ovos (\% ovos/ave/dia), peso dos ovos e massa de ovos (g/ave/dia) de poedeiras alimentadas com diferentes fracionamentos de cálcio e granulometrias de calcário.

5. Valores de consumo de ração (g/ave/dia) por período do dia (total, manhã e tarde) de poedeiras alimentadas com diferentes fracionamentos de cálcio e granulometrias de calcário

6. Desdobramento dos tratamentos referentes à característica consumo diário de ração (g/ave) de poedeiras alimentadas com diferentes fracionamentos de cálcio e granulometrias de calcário

7. Valores de consumo diário de cálcio (g/ave) por período do dia (total, manhã e tarde) de poedeiras alimentadas com diferentes fracionamentos de cálcio e granulometrias de calcário.

8. Valores de conversão alimentar ( $\mathrm{kg}$ ração/dz de ovos e $\mathrm{kg}$ de ração/kg de ovos) de poedeiras alimentadas com diferentes fracionamentos de cálcio e granulometrias de calcário.

9. Desdobramento dos tratamentos referentes à característica conversão alimentar ( $k g$ de ração/dz de ovos) de poedeiras alimentadas com diferentes fracionamentos de cálcio e granulometrias de calcário.

10. Valores de peso dos ovos (g) por período do dia (total, manhã e tarde) de poedeiras alimentadas com diferentes fracionamentos de cálcio e granulometrias de calcário.

11. Valores de percentagem de albúmen dos ovos (\%) por período do dia (total, manhã e tarde) de poedeiras alimentadas com diferentes fracionamentos de cálcio e granulometrias de calcário.

12. Valores de percentagem de gema dos ovos (\%) por período do dia 
(total, manhã e tarde) de poedeiras alimentadas com diferentes fracionamentos de cálcio e granulometrias de calcário.

13. Valores de índice de gema dos ovos por período do dia (total, manhã e tarde) de poedeiras alimentadas com diferentes fracionamentos de cálcio e granulometrias de calcário.

14. Valores de unidades Haugh dos ovos por período do dia (total, manhã e tarde) de poedeiras alimentadas com diferentes fracionamentos de cálcio e granulometrias de calcário.

15. Desdobramento dos tratamentos referentes às características peso $(\mathrm{g})$, percentagens de albúmen e gema (\%) e índice de gema dos ovos de poedeiras alimentadas com diferentes fracionamentos de cálcio e granulometrias de calcário.

16. Desdobramento dos tratamentos referentes à característica de unidades Haugh dos ovos de poedeiras alimentadas com diferentes fracionamentos de cálcio e granulometrias de calcário

17. Valores de percentagem de casca dos ovos (\%) por período do dia (total, manhã e tarde) de poedeiras alimentadas com diferentes fracionamentos de cálcio e granulometrias de calcário

18. Valores de espessura de casca dos ovos $(\mathrm{mm})$ por período do dia (total, manhã e tarde) de poedeiras alimentadas com diferentes fracionamentos de cálcio e granulometrias de calcário

19. Valores de densidade aparente dos ovos $\left(\mathrm{g} / \mathrm{mL} \mathrm{H}_{2} \mathrm{O}\right)$ por período do dia (total, manhã e tarde) de poedeiras alimentadas com diferentes fracionamentos de cálcio e granulometrias de calcário

20. Desdobramento dos tratamentos referentes à característica densidade aparente $\left(\mathrm{g} / \mathrm{mL} \mathrm{H}_{2} \mathrm{O}\right)$ de ovos coletados à tarde de poedeiras alimentadas com diferentes fracionamentos de cálcio e granulometrias de calcário.

21. Valores de solubilidade (\%) e nível de cálcio (\%) obtidos para diferentes granulometrias de calcário. 


\section{LISTA DE ABREVIATURAS}

\section{ABREVIATURA}

$\mathrm{Ca}$

CV

$\mathrm{mm}$

$\mathrm{g}$

$\mathrm{kg}$

$\mathrm{mL}$
Cálcio

Coeficiente de variação

Milímetros

Gramas

Quilogramas

Mililitros 


\section{RESUMO}

O presente estudo teve como objetivo avaliar as principais características de desempenho e qualidade interna e externa dos ovos de poedeiras comerciais brancas submetidas ao fracionamento de cálcio da dieta e diferentes granulometrias de calcário calcítico. Foram utilizadas 270 galinhas ISA-Babcock B-300 N de 40 semanas de idade por quatro períodos de 28 dias cada. $O$ delineamento experimental foi o inteiramente casualizado em arranjo fatorial $3 \times 3$, com o fatores: fracionamento de cálcio ( $2 \mathrm{~g} \mathrm{Ca}$ manhã e 2 g Ca tarde, 1 g Ca manhã e 3 g Ca tarde, e 3 g Ca manhã e $1 \mathrm{~g}$ Ca tarde) e granulometrias de calcário calcítico (mista, grossa e fina) totalizando 9 tratamentos com 5 repetições de 6 aves cada. As características de desempenho zootécnico não foram influenciadas pelos tratamentos com exceção do consumo de ração e de cálcio. $O$ fracionamento de cálcio resultou em maior consumo de ração e cálcio no período da manhã para as aves alimentadas com $3 \mathrm{~g}$ de Ca neste período do dia. Para o período da tarde, o maior consumo de ração foi observado em aves alimentadas com $3 \mathrm{~g}$ de cálcio em comparação à aves alimentadas com 1 e $2 \mathrm{~g}$ de cálcio. Não houve diferença significativa quando avaliou-se o consumo de ração total do dia. O fator granulometria do calcário não influenciou nenhum dos parâmetros estudados com exceção da densidade aparente dos ovos. A utilização de calcário calcítico fino resultou em menor densidade dos ovos em comparação ao calcário calcítico misto ou grosso. Conclui-se que a utilização de calcários com granulometria mista ou grossa beneficia a qualidade da casca dos ovos e que a prática de fracionar o oferecimento de cálcio ao longo do dia não se mostrou vantajosa. No entanto, futuras pesquisas são recomendadas envolvendo o fracionamento de outros nutrientes como fósforo, energia e proteína.

Palavras-chave: aves, cálcio, calcário, fracionamento, qualidade de casca, solubilidade de calcário 
ABSTRACT

EFFECT OF THE CALCIUM FRACTIONATION AND LIMESTONE PARTICLE SIZE ON PERFORMANCE AND EGG QUALITY OF WHITE COMMERCIAL LAYING HENS

This study was carried out to evaluate the performance and internal and external egg qualities of white commercial laying hens fed diets with different calcium levels and limestone particle sizes. Two hundred seventy ISA-Babcock B-300N hens, 40 weeks of age, were used by four - 28 days period. The experimental design was randomly in a $3 \times 3$ factorial arrangement: calcium fractionation ( $2 \mathrm{~g} \mathrm{Ca}$ morning $+2 \mathrm{~g} \mathrm{Ca}$ afternoon, $1 \mathrm{~g} \mathrm{Ca}$ morning $+3 \mathrm{~g} \mathrm{Ca}$ afternoon, $3 \mathrm{~g} \mathrm{Ca}$ morning $+1 \mathrm{~g} \mathrm{Ca}$ afternoon) and limestone particle size (blended, coarse and fine) with a total of nine treatments with five replicates of six hens each. Performance characteristics were not influenced by the treatments, except feed intake and calcium intake. It was observed higher calcium and feed intake for hens fed $3 \mathrm{~g} \mathrm{Ca}$ in the morning. Also, in the afternoon was verified higher calcium and feed intake for hens fed $3 \mathrm{~g} \mathrm{Ca}$. There was no effect of the treatments on total daily intake. The limestone particle size improved egg specific gravity when blended or coarse particle size was benefical to eggshell quality. The calcium fractionation did not show be adventageous. However, further researches are indicate to evaluate other nutrients fractionation as phosphorus, energy, and protein.

Keywords: calcium, eggshell quality, fractionation, laying hens, limestone, limestone solubility 


\section{INTRODUÇÃO}

Com os trabalhos de melhoramento genético das linhagens comerciais, as aves tornaram-se mais exigente quanto ao manejo, sanidade, ambiência e nutrição (WASHBURN, 1982).

Assim, a qualidade da casca torna-se um fator que preocupa os produtores de ovos. As perdas econômicas por danos causados à casca, resultam em depreciação e perdas de produto por presença de trincas, deformidade e irregularidades na deposição de casca. Para o consumidor, a qualidade de casca é de suma importância.

Em termos quantitativos, ROLAND (1988) relatou, em estudo de campo, perdas de até $13 \%$ dos ovos em virtude da baixa qualidade da casca na propriedade, mas que podem totalizar até $20 \%$ quando considerado o percurso até o consumidor final.

Desta maneira, persiste a importância de estudos relacionados ao processo de formação da casca visando menor quantidade de perdas e oferecendo ao consumidor um produto com qualidade.

Estudos relacionados ao processo de formação de casca demonstraram que há variação nas exigências e eficiências de absorção de cálcio pelas aves nos diferentes estágios de formação do ovo. Sabe-se que $98 \%$ da casca é formada por carbonato de cálcio, dos quais $60 \%$ constituídos por bicarbonato e 38\% por cálcio (ETCHES, 1995).

Neste sentido, a tentativa de oferecer quantidades diferentes de cálcio ao longo do processo de formação da casca do ovo para atender da melhor maneira possível as necessidades fisiológicas da ave vem sendo pesquisada (MAGGIONI et al. 1996; KESHAVARZ, $1998^{\mathrm{a}}$ e 1998 ${ }^{\mathrm{b}}$ ). 
O uso de granulometrias distintas para as fontes de cálcio tem sido mais rotineiro. Mas, existem diferenças entre os produtos de diferentes regiões de origem, exemplo à solubilidade e nível de cálcio. Logo, também são necessários mais estudos de identificação destes parâmetros para que a sua utilização não comprometa parâmetros produtivos e de qualidade dos ovos.

Por isso, mais estudos são necessários visando uma abordagem com enfoque mais prático na tentativa de solucionar parcialmente os problemas de qualidade de casca que têm início em poedeiras com mais de 40 semanas de idade.

O presente trabalho avaliou as principais características de desempenho e qualidade interna e externa de ovos de poedeiras comerciais brancas sob o efeito do fracionamento de cálcio e granulometrias de calcário. 


\section{REVISÃO DE LITERATURA}

\subsection{Formação da casca e fracionamento de cálcio}

Cerca de $10 \%$ do peso do ovo é composto pela casca (ETCHES, 1995). A ave necessita de aproximadamente 2,0 gramas de cálcio para formar uma casca com qualidade (SCOTT, 1991) e 0,5 grama para a formação da gema (LENNARDS et al., 1981).

A casca é composta por bicarbonato de cálcio (98\%) e uma matriz glicoprotéica (2\%), sendo que $40 \%$ da molécula do bicarbonato de cálcio é cálcio (ETCHES, 1995). Durante o processo de formação da casca, $70 \%$ do cálcio provêm da alimentação e $30 \%$ dos ossos medulares, ambos transportados através do tecido sangüíneo.

Como cerca de 50 a $60 \%$ do cálcio dietético é utilizado no processo de formação da casca, a poedeira necessita de um consumo diário aproximado de 4,0 gramas de cálcio (MILES, 2000). Atualmente as exigências deste mineral são consideradas para um aproveitamento de $70 \%$, mas isto não ocorre durante todo o ciclo ovulatório da ave. 
A formação do ovo é um processo longo, desde a maturação da gema até a postura, requer de 24 a 26 horas, das quais 20 são destinadas para a formação da casca (SWENSON e REECE, 1996).

A casca é secretada mais ativamente durante as últimas $10-15$ horas em que o ovo permanece no útero (ROLAND et al., 1973 ${ }^{b}$ ). Esta atividade de calcificação aumenta gradativamente 3 horas após a entrada do ovo no útero (COLE e HARESIGN, 1986). Segundo IEDA et al. (1995) a presença do ovo na glândula da casca (útero) estimula a síntese e acúmulo de calbidina (proteína carreadora de cálcio) e receptores de vitamina D neste órgão.

O cálcio influencia a ingestão de alimento e a ave possui a capacidade de regular sua ingestão de acordo com as necessidades fisiológicas durante o processo de formação do ovo (HURWITZ e BAR, 1969). Também há influência sobre a absorção intestinal de cálcio. Quando a glândula da casca (útero) está inativa, sem a presença do ovo, a absorção de cálcio pelo intestino é em torno de 40\%. Quando a mesma está ativa, a eficiência de absorção chega a mais de 70\% (CLUNIES e LEESON, 1995).

Assim, apenas durante o período de 6 a 12 horas antes da postura haveria deficiência de cálcio, fazendo com que a mobilização do cálcio dos ossos medulares seja necessária (CLUNIES e LEESON, 1995). Mas, quando há deficiência de cálcio dietético, o cálcio medular não consegue suprir as exigências para a formação de uma boa casca, podendo resultar em problemas para as aves como a fadiga de gaiola (ROLAND et al., 1972; HARMS, $1991^{\mathrm{a}}$ e SCOTT, 1991). 
Quando a ingestão de cálcio é adequada, as necessidades de cálcio podem ser supridas através do aumento na absorção intestinal. Porém, havendo ingestão inadequada, este aumento não é suficiente para garantir o suprimento de cálcio.

Desta maneira, o cálcio está em estado dinâmico, sendo mobilizado e depositado continuamente. Estas características podem resultar em diferenças entre os ovos postos no período da manhã e da tarde (HARMS, $\left.1991^{a}\right)$.

Quando as aves tornam-se mais velhas, há diminuição nos níveis de 1- $\alpha$-hidroxilase (enzima responsável pela ativação do metabólito da Vitamina D nos rins) e redução na eficiência de absorção de cálcio, consequentemente, qualidade de casca inferior e aumento na perda de ovos. Associado a isto, o aumento no tamanho do ovo favorece a redução na qualidade da casca, pois a taxa de aumento de peso do ovo é superior à taxa de aumento no volume de casca com o avançar da idade das aves (ADAMS e BELL, 1998). Também, as aves mais velhas possuem menor capacidade de repor o cálcio perdido em períodos de hopocalcemia quando comparadas a aves jovens (ELAROUSSI et al., 1994).

Baseados nos conhecimentos sobre o processo de formação da casca durante o ciclo ovulatório da ave, diversos estudos foram feitos na tentativa de melhorar a qualidade da casca nos momentos de maior exigência da ave.

Os primeiros foram relacionados com suplementação de cálcio no período da tarde. Estudos mais recentes em matrizes pesadas demonstram 
que a suplementação de cálcio melhora a qualidade de casca sem comprometer a eclosão dos ovos (NORDSTROM, 1980; BRAKE, 1988; REIS et al., 1995 e NOVO et al., 1997). Porém, segundo FARMER e ROLAND (1986), o uso de suplementos à tarde pode ser desfavorecido pela menor quantidade de alimento e/ou matéria seca disponível na moela para solubilização das fontes de cálcio, limitando os resultados deste manejo alimentar.

Outra técnica, conhecida com "lanche da meia-noite" (midnight feeding ou midnight snack), consiste no oferecimento de luz por um período de 1 a 2 horas durante o período noturno, quando as reservas de cálcio na moela estão baixas (HARMS et al., 1996). Desta maneira, as aves se alimentam podendo rennovar as reservas de cálcio bem como compensar o consumo de ração deprimido durante o dia por fatores climáticos como o calor excessivo. Mas este procedimento também poderá ser inviável para regiões onde há deficiência no fornecimento de energia às granjas comerciais.

Assim, o desenvolvimento de trabalhos relacionados a dietas distintas em diferentes momentos do dia merece destaque.

Estudos de LEESON e SUMMERS (1980) e CLASSEN e SCOTT (1982) indicam que desde o início do período produtivo, as aves têm a capacidade de selecionar dietas para atender suas exigências de cálcio. HOLCOMBE et al. (1977) observaram que as aves aumentam o consumo de ração no período da manhã para repor a demanda noturna e no início da 
tarde devido ao aumento na demanda de cálcio para a formação da casca durante o período noturno.

Oferecendo livre acesso a fontes de cálcio, energia e proteína separadas entre si num sistema denominado cafeteria, CHAH e MORAN (1985) observaram que houve aumento no consumo de cálcio à partir das 16 horas, enquanto que o consumo de energia e proteína foi maior nas primeiras horas do dia. O aumento no consumo de cálcio foi constatado no início da tarde e nas primeiras horas de iluminação no período da manhã.

HOLCOMBE et al. (1975) e HARMS (1991 ${ }^{\text {b }}$ ) ao oferecerem a opção de dietas com mais cálcio, observaram maior consumo destas no começo da manhã e início da tarde. Aves com dietas deficientes em cálcio, mas com acesso a fontes suplementares não tiveram comprometimento da casca (JOSHUA e MULLER, 1979).

O oferecimento de dietas com diferentes quantidades de cálcio, energia e proteína ao longo do dia pode reduzir o consumo de ração em até $7 \%$, sem comprometimento da produção e qualidade da casca (LEESON e SUMMERS, 1979).

Aves alimentadas com mais energia e proteína no período da manhã e mais cálcio no período da tarde obtiveram menor quantidade de ovos pequenos e/ou com baixa quantidade de casca (REICHMANN e CONNOR, 1979).

Usando farinha de ostras como fontes de cálcio, MAGGIONI et al. (1996) encontraram maior resistência da casca nos ovos de poedeiras semipesadas alimentadas com rações contendo $2,25 \%$ de cálcio durante a 
manhã e 4,75\% no período da tarde. Não foi encontrada diferença na produção de ovos comprando-se com aves alimentadas com ração contendo $3,5 \%$ de cálcio ao longo do dia.

KESHAVARZ $\left(1998^{\mathrm{a}}\right.$ e $\left.1998^{\mathrm{b}}\right)$ experimentou dietas contendo de 1,5 a 2,5\% de cálcio entre 05 e 15 horas e dietas com 4,5 a 5,5\% de cálcio entre 15 e 21 horas para poedeiras Babcock B-300 com 31 semanas de idade. Não houve diferença significativa no consumo de ração, produção de ovos, peso dos ovos, massa de ovos, conversão alimentar, ganho de peso e densidade aparente em comparação à dieta contendo 3,5\% de cálcio.

Segundo NIR et al. (1996) a restrição de determinados nutrientes por curtos períodos de tempo favorece o desenvolvimento da ave, proporcionando diminuição na motilidade da ingesta no trato gastrintestinal. As aves aprendem rapidamente a ingerir a quantidade de nutrientes necessária quando expostos a períodos restritos de oferecimento.

\subsection{Granulometria e solubilidade do calcário}

Uma vez iniciada a produção, a ave necessita consumir em torno de 4,0 gramas de cálcio por dia a fim de produzir ovos com uma quantidade adequada de casca. Farinha de ostras e calcário calcítico são duas excelentes fontes de cálcio para poedeiras.

Durante o dia, a principal fonte de cálcio para a formação da casca é a alimentação e durante a noite, há necessidade de mobilização do cálcio ósseo (BELYAVIN, 1987). Para a formação da casca, as aves têm a 
capacidade de manter reservas de cálcio e fósforo principalmente nos ossos longos (COLE e HARESIGN, 1986; ETCHES, 1995).

Cerca de 30 a $40 \%$ do cálcio destinado para a formação da casca do ovo é proveniente dos ossos medulares. Quanto maior for a dependência desta fonte para a formação da casca, menor será a deposição deste mineral na mesma. Mas, esta mobilização pode ser reduzida em até $15 \%$ quando há suprimento de cálcio dietético durante este período de mobilização (FARMER et al., 1986 ${ }^{\text {}}$ ).

À noite, quando o trato digestório das aves está vazio, os ossos são a principal fonte de cálcio para a formação da casca, já que as partículas finas de calcário são rapidamente solubilizadas na moela (HARMS, 1982). Logo, a granulometria das fontes de cálcio pode influenciar a disponibilidade deste mineral para a ave.

Quando são usadas partículas maiores de calcário, com menor solubilidade, o trato digestório das aves poderá conter cálcio mesmo no período noturno. Havendo solubilização gradativa e disponibilidade para ser absorvido para a corrente sangüínea (MILES, 2000).

Se a dieta não contém partículas maiores de calcário ou farinha de casca de ostras, é possível observar uma deterioração na qualidade da casca. Os ossos de poedeiras mais velhas podem se tornar mais frágeis e menos densos (McNAUGHTON, 1981; GUINOTTE et al., 1991).

GUINOTTE e NYS $\left(1991^{\mathrm{a}}\right)$ observaram maior resistência da casca, peso do ovo e peso da casca quando foram oferecidas a poedeiras semipesadas fontes de cálcio com maior tamanho de partícula. Os autores 
atribuíram os resultados a uma maior retenção destes ingredientes no papo e moela das aves. Não foram observadas alteração na estrutura e resistência óssea das aves.

Estudos realizados por ROLAND (1986b) e SCHEIDELER (1998) indicam que a proporção de 33\% de calcário grosso/farinha de ostras e $67 \%$ de calcário fino poderia ser a mais adequada considerando-se fontes de cálcio com granulometrias distintas. Segundo MUIRHEAD (1991) a presença de partículas maiores de fontes de cálcio favorece a ave a ingeri-las momentos antes do período de escuro, fazendo com que haja cálcio disponível para a formação da casca do ovo com menor mobilização do cálcio ósseo e sem comprometimento da estrutura da ave.

Estudando as fontes de cálcio, uma vasta revisão de literatura realizada por ROLAND $\left(1986^{b}\right)$ demonstra que o uso de farinha de ostras resulta em melhor qualidade de casca quando comparada ao calcário granular fino e, resultados semelhantes quando comparada ao calcário granular de granulometria semelhante (3 a $5 \mathrm{~mm}$ de diâmetro). Neste ponto, a descrição da solubilidade das fontes de cálcio utilizadas se faz necessária pois existem resultados contraditórios na literatura à exemplo do traBalho de MARCH e AMIN (1981) onde a suplementação de farinha de ostras foi benéfica para a qualidade de casca em relação ao calcário grosso.

SCOTT (1991) relata que, além da granulometria das fontes de cálcio, deve-se levar em consideração a solubilidade das fontes utilizadas. Para este parâmetro foram encontradas variações de até $200 \%$ para um mesmo ingrediente. 
CHENG e COON $\left(1990^{\circ}\right)$ relatam que a solubilidade ideal para os calcários é em torno de 15\%, visando melhores resultados para qualidade de casca e cinza ósseas. Foram encontradas correlações negativas entre solubilidade das fontes de cálcio e peso de casca por unidade de área e densidade aparente dos ovos. Mas ressaltam que a relação entre solubilidade dos calcários para as diversas granulometrias não é linear. SCOTT (1991) salienta que existe variação na solubilidade das fontes de cálcio de mesma granulometria para locais de origem distintos.

Estudos relacionados à metadologia para a determinação da solubilidade das fontes de cálcio também devem ser considerados pois foram encontradas diferenças de resultados para as diversas metodologias, conforme estudo realizado por CHENG e COON (1990 $\left.{ }^{b}\right)$. 


\section{MATERIAL E MÉTODOS}

\subsection{Local e período}

O experimento foi realizado no aviário experimental do Campus Administrativo de Pirassununga da Universidade de São Paulo, com duração de 16 semanas, divididas em quatro períodos de quatro semanas cada, de 11/04/01 a 31/07/01.

\subsection{Animais experimentais e delineamento experimental}

Foram utilizadas 270 aves da linhagem comercial ISA-Babcock B-300 $\mathrm{N}$, com 40 semanas de idade, distribuídas em 45 parcelas, sendo cada unidade experimental composta por seis aves.

Foi utilizado o delineamento experimental inteiramente ao acaso, em arranjo fatorial $3 \times 3$, com os fatores: fracionamento da quantidade de cálcio por ave e por período do dia (2g manhã:2g tarde, $1 \mathrm{~g}$ manhã:3g tarde e $3 \mathrm{~g}$ manhã:1g tarde) e granulometria de calcário (mista, grossa e fina), totalizando 9 tratamentos, com 5 repetições de seis aves cada (Tabela 1). 
Tabela 1 - Relação de tratamentos experimentais

\begin{tabular}{lccc}
\hline Tratamento & $\begin{array}{c}\text { Fracionamento de cálcio } \\
\text { Manhã }\end{array}$ & $\begin{array}{c}\text { (g Ca / ave }) \\
\text { Tarde }\end{array}$ & Granulometria do calcário* \\
\hline A & 2 & 2 & Mista \\
B & 2 & 2 & Grossa \\
C & 2 & 2 & Mina \\
D & 1 & 3 & Gista \\
E & 1 & 3 & Fina \\
F & 1 & 3 & Mista \\
G & 3 & 1 & Grossa \\
H & 3 & 1 & Fina \\
I & 3 & 1 &
\end{tabular}

\subsection{Instalações e equipamentos}

As aves foram alojadas aos pares em gaiolas de arame galvanizado medindo $0,25 \times 0,45 \times 0,40 \mathrm{~m}$ (frente, profundidade $\mathrm{e}$ altura, respectivamente), dispostas em linha e providas de comedouro tipo calha de chapa galvanizada e bebedouros do tipo "nipple".

As aves foram alojadas com 16 semanas de idade, em 03/10/01 e submetidas aos critérios de manejo e nutrição que constam no manual de manejo da linhagem (ISA-Babcock, 2000) até o início do período experimental.

O programa de luz adotado foi de 16 horas durante a fase de produção, acesas às 4:00 e apagadas às 20:00 horas.

As temperaturas e umidades relativas máxima e mínima foram registradas diariamente 4 vezes ao dia, à partir das 7:00 horas, em intervalos de 4 horas cada com auxílio de termômetro digital. As temperaturas médias, máximas e mínimas foram $20,59 \pm 0,43 ; 25,43 \pm 1,43$ e $15,75 \pm 0,72$, 
respectivamente. As umidades relativas do ar médias, máximas e mínimas foram $66 \pm 6,09 ; 71 \pm 6,09$ e $62 \pm 6,09$, respectivamente.

\subsection{Rações experimentais}

As rações experimentais foram formuladas à base de milho e farelo de soja com os níveis nutricionais visando atender as necessidades das aves para um consumo de 110 gramas/dia conforme manual da linhagem ISA-Babcock B-300 N (2.000) e são apresentadas na Tabela 2.

Tabela 2 - Níveis nutricionais e composição das rações experimentais

\begin{tabular}{lccc}
\hline Ingrediente & \multicolumn{3}{c}{$\%$} \\
\hline Milho moído & 60,3 & 62,5 & 59,0 \\
Farelo de soja & 16,2 & 19,1 & 20,5 \\
Calcário calcítico & 3,5 & 8,6 & 11,9 \\
Farinha de carne e ossos & 4,1 & 4,1 & 4,1 \\
Farelo de trigo & 8,5 & 3,4 & 1,5 \\
Protenose & 1,5 & 1,5 & 1,5 \\
Suplmento vitamínico e mineral ${ }^{*}$ & 0,5 & 0,5 & 0,5 \\
Sal comum & 0,3 & 0,3 & 0,3 \\
Óleo de soja & 0,0 & 0,0 & 1,5 \\
\hline
\end{tabular}

Rações experimentais (g de cálcio)

\begin{tabular}{lccc} 
Nutriente & 1 & 2 & 3 \\
\hline Energia metabolizável (kcal/kg) & 2.750 & 2.750 & 2.750 \\
Proteína Bruta (\%) & 17,00 & 17,00 & 17,00 \\
Cálcio (\%) & 2,00 & 4,00 & 6,00 \\
Fósforo Total (\%) & 0,60 & 0,60 & 0,60 \\
Fósforo Disponível (\%) & 0,39 & 0,39 & 0,39 \\
Metionina (\%) & 0,39 & 0,39 & 0,39 \\
Metionina + Cistina (\%) & 0,69 & 0,69 & 0,69 \\
\hline
\end{tabular}

${ }^{*}$ Fornecimento por kg de dieta: Vit. A $6.250 \mathrm{UI}$, Vit. E $15 \mathrm{UI}$, Vit. K 0,40 mg, Vit B1 0,25 mg, Vit B2 3,40 mg, Vit B6 0,25 mg, Vit B12 $20 \mathrm{mcg}$, Ác. Pantotênico 3,80 mg, Niacina 9,90 mg, Biotina, 0,10 mg, Ác. Fólico 0,25 mg, Cobre 6,00 mg, Ferro, 52,5 mg, lodo 0,33 mg, Selênio $0,21 \mathrm{mg}$, Manganês 48,00 mg, Zinco 60,00 mg, Antioxidante 0,40 mg, Q.S.P. $1000 \mathrm{~g}$. 
As rações foram oferecidas em dois horários, às 8:00 e às 16:00 horas. As mesmas foram acondicionadas em baldes plásticos distintos conforme o período do dia (manhã e tarde). O consumo de ração foi calculado semanalmente com realização de análises estatísticas em intervalos de 4 semanas.

As granulometrias dos calcários utilizados foram assim classificadas: fina - granulometria inferior a $0,5 \mathrm{~mm}$ e; grossa - granulometria superior a $3,0 \mathrm{~mm}$. A granulometria mista foi obtida através da mistura de $30 \%$ de calcário grosso e $70 \%$ de calcário fino, seguindo recomendações de SCHEIDELER (1998).

\subsection{Características avaliadas}

\subsubsection{Características de desempenho zootécnico}

Foram avaliadas as características de produção de ovos (\% ovos/ave/dia), consumo de ração e cálcio (g/ave/dia), conversão alimentar (g ração/g ovo e g ração/dz de ovos), peso dos ovos (g) e massa de ovos (g/ave/dia).

A produção de ovos foi registrada diariamente e o cálculo realizado ao final de cada período experimental. A massa de ovos é resultante da multiplicação do peso médio dos ovos pela percentagem de produção dos mesmos. 
O consumo de ração e cálcio foi analisado por período de consumo (manhã e tarde) e total consumido no dia.

\subsubsection{Características de qualidade interna dos ovos}

Foram avaliadas as características de percentagem de albúmen e de gema (\%), unidade Haugh e índice de gema. Para o cálculo de unidade Haugh e índice de gema foram utilizadas as fórmulas descritas por NESHEIM et al. (1979).

Os dados utilizados para o cálculo destas características foram obtidos dos ovos coletados nos dois últimos dias de cada período experimental e identificados quanto à parcela experimental, repetição e período da coleta (ovos postos de 0 a 8 horas do programa de luz e ovos postos de 8 a 16 horas do programa de luz).

Os ovos foram pesados individualmente e posteriormente quebrados para pesagem dos constituintes do ovo. Para a determinação dos pesos foi utilizada uma balança digital (Marte - código AS 2000) com precisão de 0,01 $g(25-2000 \mathrm{~g})$.

A medida da altura de clara e de gema foi realizada com uso de um altímetro (Ames código S-6428) e o diâmetro de gema com um paquímetro.

\subsubsection{Características de qualidade externa dos ovos}

Foram avaliadas as características de qualidade externa dos ovos, expressas como percentagem de casca, espessura da casca (mm) e 
densidade aparente dos ovos $\left(\mathrm{g} / \mathrm{mL} \mathrm{H}_{2} \mathrm{O}\right)$. Os dados utilizados para os cálculos destas características foram obtidos dos ovos coletados nos dois últimos dias de cada período experimental e identificados quanto à parcela experimental, repetição e período da coleta (ovos postos de 0 a 8 horas do programa de luz e ovos postos de 8 a 16 horas do programa de luz).

A medida de densidade aparente dos ovos seguiu recomendação de MORENG e AVENS (1990) utilizando 13 soluções salinas com variação na densidade específica entre 1,065 e $1,095 \mathrm{~g} / \mathrm{mL} \mathrm{H}_{2} \mathrm{O}$ com intervalos de 0,0025, determinados através de densímetro graduado (Incoterm 2535) com escala de 1,050 a $1,100 \mathrm{~g} / \mathrm{mL} \mathrm{H}_{2} \mathrm{O}$ e precisão de 0,0005 .

As cascas foram secas à temperatura ambiente durante 7 dias para posteriormente serem pesadas (para cálculo de percentagem de casca) e terem a espessura medidas na região mediana com um micrômetro (Mitsutoyo - código 7313) com precisão de 0,01 mm e escala de 0,01 a $10,00 \mathrm{~mm}$.

\subsubsection{Solubilidade das fontes de cálcio}

A solubilidade dos calcários foi determinada através de metodologia descrita por ZHANG e COON (1997 $)$, através da pesagem de 2,0 gramas de cada amostra de calcário (mista, grossa e fina) e imersas em solução aquecida a $35^{\circ} \mathrm{C}$ de $0,2 \mathrm{~N}$ de ácido clorídrico por 15 minutos sob leve agitação. Posteriormente, as amostras foram filtradas em papel de filtro Wattmann 40 , secas em estufa à $60^{\circ} \mathrm{C}$ por 20 horas e pesadas em balança 
digital para cálculo de percentagem de solubilização do calcário in vitro. Os valores obtidos encontram-se na Tabela 3.

Tabela 3. Valores de solubilidade (\%) e nível de cálcio (\%) obtidos para as diferentes granulometrias de calcário

\begin{tabular}{lcc}
\hline Granulometria do calcário & Solubilidade (\%) & Cálcio (\%) \\
\hline Fina & 50,10 & 35,00 \\
Grossa & 20,50 & 36,00 \\
Mista (70\% Fina + 30\% Grossa) - obtido & 41,60 & 35,50 \\
Mista (70\% Fina + 30\% Grossa) - estimado & 41,25 & 35,30 \\
\hline
\end{tabular}

\subsection{Análise estatística}

Os dados obtidos foram analisados com auxílio do programa ESTAT 2.0 - Sistema para Análise Estatística (1992) e as médias dos tratamentos comparadas pelo teste de Tukey ao nível de $5 \%$ de probabilidade.

Segue abaixo o esquema de análise de variância:

\begin{tabular}{lc}
\hline Causas de variação & Graus de liberdade \\
\hline Fracionamento de cálcio $(\mathrm{A})$ & 2 \\
Granulometria do calcário $(\mathrm{B})$ & 2 \\
Interação $(\mathrm{A}$ x B) & 4 \\
\hline (Tratamentos) & $(8)$ \\
Resíduo & 36 \\
\hline Total & 44 \\
\hline
\end{tabular}




\section{RESULTADOS E DISCUSSÃO}

\subsection{Características de desempenho zootécnico}

Os dados referentes às características de desempenho zootécnico encontram-se na Tabela 4. Não houve diferença nem interação $(P>0,05)$ entre os fatores estudados para os parâmetros de produção de ovos, peso dos ovos e massa de ovos durante todo o período experimental. Porém, foi encontrada diferença significativa $(P<0,05)$ no segundo período experimental onde o uso de calcário grosso resultou em menor peso dos ovos em comparação a aves alimentadas com calcário fino.

$\mathrm{Na}$ Tabela 5 estão os valores de consumo de ração total do dia (g/ave/dia) e consumo de ração (g/ave) nos períodos da manhã e da tarde. Não houve diferença nem interação $(P>0,05)$ entre os fatores estudados para o consumo de ração total do dia. Entretanto, foram observadas diferenças $(P>0,05)$ para o consumo de ração quando analisado por período de consumo (manhã ou tarde) para o fator fracionamento de cálcio.

No período da manhã, as aves alimentadas com diferentes sistemas de fracionamento de cálcio (2:2, 1:3 e 3:1) apresentaram o seguinte comportamento de consumo: 52,35, 49,54 e 54,87 g ração/ave. Esta diferença manteve-se durante os períodos experimentais 1 e 2; nos períodos experimentais 3 e 4, as aves alimentadas com fracionamento de cálcio 1:3 
apresentaram menor consumo de ração quando comparadas às demais (2:2 e 3:1). No período da tarde, as aves alimentadas com fracionamento de cálcio 1:3 apresentaram maior consumo de ração quando comparadas às demais (2:2 e 3:1). Também foram observadas interações entre os fatores durante os períodos experimentais 1 e 2 do período da manhã e 2 do período da tarde (Tabela 6).

O desdobramento dos resultados obtidos mostra que o fracionamento de cálcio resultou em menor consumo de ração no período da manhã quando usou-se calcário fino ou grosso durante os períodos experimentais 1 e 2. Esta diferença também foi observada para o consumo de ração da tarde durante o período experimental 2. A análise do fator granulometria do calcário indicou menor consumo de ração para as aves alimentadas com o calcário fino em comparação aos demais tipos de calcário.

O consumo de cálcio (g/ave/dia) não apresentou diferença nem interação $(P>0,05)$ para os fatores estudados (Tabela 7). Entretanto, quando o consumo de cálcio foi analisado por período do dia (manhã e tarde) podem ser observadas diferenças significativas $(P<0,05)$. As aves alimentadas no sistema de fracionamento de cálcio 1:3 consumiram menor quantidade de cálcio no período da manhã $(0,99 \mathrm{~g}$ Ca/ave) quando comparadas às aves alimentadas com fracionamento $2: 2$ e 3:1 (2,09 e 3,29 g Ca/ave, respectivamente). No período da tarde, as aves que apresentaram menor consumo de cálcio (1,02 g Ca/ave) foram submetidas ao fracionamento 3:1. As aves alimentadas no sistema de fracionamento 2:2 e 1:3 consumiram no período da tarde 2,09 e 3,20 g Ca/ave respectivamente. Não foram 
encontradas diferenças estatísticas para o fator granulometria ou interação entre os fatores estudados $(P>0,05)$.

As conversões alimentares (kg ração/dz de ovo e kg ração/kg de ovo) não foram influenciadas $(P>0,05)$ pelos fatores estudados através da análise das médias de todo o período experimental (Tabela 8). Contudo, foi observada interação $(\mathrm{P}<0,05)$ para a conversão alimentar $(\mathrm{kg}$ ração/dz de ovos), cujo desdobramento encontra-se na Tabela 9. O uso de granulometria mista de calcário resultou em melhor conversão alimentar comparando o desempenho produtivo das aves associado ao sistema de fracionamento de cálcio 2:2. Por outro lado, o uso de calcário fino ou grosso resultou em melhor conversão alimentar quando conjugado ao sistema de fracionamento de cálcio 1:3.

Também, durante o segundo período experimental as aves alimentadas pelo sistema de fracionamento 3:1 apresentaram pior conversão alimentar (1,79 kg ração/kg de ovos) comparando-se aos demais tratamentos 2:2 e 1:3 (1,65 e 1,57 kg ração/dz de ovos) respectivamente.

A formulação de ração mostrou-se adequada ao consumo de ração apresentado pelos animais experimentais.

Os resultados obtidos no presente estudo concordam com diversos trabalhos publicados anteriormente. 
Tabela 4 - Valores de produção de ovos (\% ovos/ave/dia), peso dos ovos (g) e massa de ovos (g/ave/dia) de poedeiras alimentadas com diferentes fracionamentos de cálcio e granulometrias de calcário

\begin{tabular}{|c|c|c|c|c|c|c|c|c|}
\hline \multirow[t]{2}{*}{ Característica } & \multirow[t]{2}{*}{ Período } & \multicolumn{3}{|c|}{ Fracionamento de cálcio (g manhã : g tarde) } & \multicolumn{3}{|c|}{ Granulometria de calcário $^{1}$} & \multirow[t]{2}{*}{ CV (\%) } \\
\hline & & $2: 2$ & $1: 3$ & $3: 1$ & Mista & Grossa & Fina & \\
\hline Produção de ovos & $\begin{array}{l}1 \\
2 \\
3 \\
4 \\
\text { Geral }\end{array}$ & $\begin{array}{l}86,71 \\
86,07 \\
86,90 \\
83,49 \\
85,80 \\
\end{array}$ & $\begin{array}{l}85,24 \\
85,44 \\
83,25 \\
82,46 \\
84,08 \\
\end{array}$ & $\begin{array}{l}84,32 \\
85,36 \\
83,57 \\
82,86 \\
84,03\end{array}$ & $\begin{array}{l}85,79 \\
87,54 \\
85,72 \\
83,02 \\
85,52 \\
\end{array}$ & $\begin{array}{l}84,05 \\
85,95 \\
82,62 \\
82,81 \\
83,22 \\
\end{array}$ & $\begin{array}{l}86,43 \\
83,37 \\
85,40 \\
82,98 \\
85,17\end{array}$ & $\begin{array}{l}5,89 \\
6,58 \\
6,29 \\
6,26 \\
4,69 \\
\end{array}$ \\
\hline Peso dos ovos & $\begin{array}{l}1 \\
2 \\
3 \\
4 \\
\text { Geral }\end{array}$ & $\begin{array}{l}62,71 \\
63,52 \\
64,69 \\
64,90 \\
64,37\end{array}$ & $\begin{array}{l}62,16 \\
63,06 \\
62,96 \\
63,54 \\
62,58 \\
\end{array}$ & $\begin{array}{l}61,96 \\
62,04 \\
63,89 \\
64,00 \\
62,43 \\
\end{array}$ & $\begin{array}{c}62,24 \\
62,85 \mathrm{ab} \\
64,20 \\
63,50 \\
63,06\end{array}$ & $\begin{array}{c}61,75 \\
61,84 \text { b } \\
63,46 \\
62,65 \\
62,88\end{array}$ & $\begin{array}{c}62,84 \\
63,94 \text { a } \\
63,87 \\
63,50 \\
63,44\end{array}$ & $\begin{array}{l}4,56 \\
3,57 \\
3,84 \\
6,10 \\
3,43\end{array}$ \\
\hline Massa de ovos & $\begin{array}{l}1 \\
2 \\
3 \\
4 \\
\text { Geral }\end{array}$ & $\begin{array}{l}54,03 \\
55,15 \\
56,03 \\
54,54 \\
52,69\end{array}$ & $\begin{array}{l}52,57 \\
53,71 \\
54,11 \\
54,29 \\
50,92\end{array}$ & $\begin{array}{l}52,54 \\
54,75 \\
53,24 \\
54,36 \\
50,54\end{array}$ & $\begin{array}{l}53,71 \\
54,10 \\
54,75 \\
54,44 \\
52,04\end{array}$ & $\begin{array}{l}52,92 \\
54,57 \\
53,40 \\
54,27 \\
50,57\end{array}$ & $\begin{array}{l}53,50 \\
54,94 \\
55,23 \\
54,49 \\
51,54\end{array}$ & $\begin{array}{l}7,72 \\
6,61 \\
6,30 \\
8,62 \\
6,51\end{array}$ \\
\hline
\end{tabular}

Médias seguidas de letras diferentes em cada linha e em cada fator diferem entre si pelo teste de Tukey $(p<0,05)$

1 Granulometria dos calcários $(\mathrm{mm})$ : Mista $=30 \%$ de calcário grosso e $70 \%$ de calcário fino; Grossa: entre 3,0 e 5,0 mm; Fina: inferior a 0,5 mm 
Tabela 5 - Valores de consumo de ração (g/ave/dia) por período do dia (total, manhã e tarde) de poedeiras alimentadas com diferentes fracionamentos de cálcio e granulometrias de calcário

\begin{tabular}{|c|c|c|c|c|c|c|c|c|}
\hline \multirow[t]{2}{*}{ Característica } & \multirow[t]{2}{*}{ Período } & \multicolumn{3}{|c|}{ Fracionamento de cálcio (g manhã : g tarde) } & \multicolumn{3}{|c|}{ Granulometria de calcário } & \multirow[t]{2}{*}{ CV $(\%)$} \\
\hline & & $2: 2$ & $1: 3$ & $3: 1$ & Mista & Grossa & Fina & \\
\hline Total do dia & $\begin{array}{l}1 \\
2 \\
3 \\
4 \\
\text { Geral }\end{array}$ & $\begin{array}{l}103,29 \\
104,60 \\
105,51 \\
105,04 \\
104,60\end{array}$ & $\begin{array}{l}102,44 \\
104,74 \\
105,79 \\
104,69 \\
104,42\end{array}$ & $\begin{array}{l}103,20 \\
105,83 \\
104,96 \\
104,46 \\
104,62\end{array}$ & $\begin{array}{l}103,70 \\
104,44 \\
105,38 \\
104,92 \\
104,77 \\
\end{array}$ & $\begin{array}{l}101,88 \\
103,68 \\
104,85 \\
104,38 \\
103,68 \\
\end{array}$ & $\begin{array}{l}103,34 \\
104,89 \\
106,02 \\
104,90 \\
104,89 \\
\end{array}$ & $\begin{array}{l}4,52 \\
4,40 \\
4,82 \\
4,50 \\
4,40\end{array}$ \\
\hline Período da manhã & $\begin{array}{l}1^{*} \\
2^{*} \\
3 \\
4 \\
\text { Geral }\end{array}$ & $\begin{array}{c}51,75 \\
52,45 \\
52,86 \mathrm{ab} \\
52,44 \mathrm{a} \\
52,35 \mathrm{~b}\end{array}$ & $\begin{array}{c}48,51 \\
49,39 \\
50,88 \mathrm{~b} \\
49,54 \mathrm{~b} \\
49,54 \mathrm{c}\end{array}$ & $\begin{array}{c}54,35 \\
55,35 \\
55,16 \text { a } \\
54,61 \text { a } \\
54,87 \text { a }\end{array}$ & $\begin{array}{l}52,21 \\
52,72 \\
53,23 \\
52,63 \\
52,63\end{array}$ & $\begin{array}{l}51,13 \\
51,81 \\
53,17 \\
51,97 \\
51,85\end{array}$ & $\begin{array}{l}52,21 \\
52,65 \\
52,50 \\
51,98 \\
52,27\end{array}$ & $\begin{array}{l}4,79 \\
4,86 \\
5,48 \\
5,02 \\
4,78 \\
\end{array}$ \\
\hline Período da tarde & $\begin{array}{l}1 \\
2^{*} \\
3 \\
4 \\
\text { Geral }\end{array}$ & $\begin{array}{c}51,54 \\
52,09 \\
52,65 a b \\
52,70 a b \\
52,24 \mathrm{~b}\end{array}$ & $\begin{array}{c}53,93 \\
55,35 \\
55,08 \text { a } \\
55,14 \text { a } \\
53,39 \text { a }\end{array}$ & $\begin{array}{c}48,85 \\
49,39 \\
49,81 \mathrm{~b} \\
49,86 \mathrm{~b} \\
50,97 \mathrm{c}\end{array}$ & $\begin{array}{l}51,50 \\
52,36 \\
52,33 \\
52,38 \\
52,14\end{array}$ & $\begin{array}{l}50,76 \\
51,81 \\
52,35 \\
52,40 \\
51,83\end{array}$ & $\begin{array}{l}52,06 \\
52,65 \\
52,85 \\
52,90 \\
52,62\end{array}$ & $\begin{array}{l}6,38 \\
5,45 \\
6,40 \\
6,40 \\
5,45\end{array}$ \\
\hline
\end{tabular}

Médias seguidas de letras diferentes em cada linha e em cada fator diferem entre si pelo teste de Tukey $(p<0,05)$

1 Granulometria dos calcários $(\mathrm{mm})$ : Mista $=30 \%$ de calcário grosso e $70 \%$ de calcário fino; Grossa: entre 3,0 e 5,0 mm; Fina: inferior a 0,5 mm

* Houve interação significativa e o desdobramento dos tratamentos encontra-se na Tabela 6 
Tabela 6 - Desdobramento dos tratamentos referentes à característica consumo diário de ração (g/ave) de poedeiras alimentadas com diferentes fracionamentos de cálcio e granulometrias de calcário

\begin{tabular}{|c|c|c|c|}
\hline \multirow{2}{*}{$\begin{array}{l}\text { Fracionamento de cálcio } \\
\text { (g manhã : g tarde) }\end{array}$} & \multicolumn{3}{|c|}{ Granulometrias de Calcário } \\
\hline & Mista & Grossa & Fina \\
\hline & \multicolumn{3}{|c|}{ Consumo diário de ração - Período 1 - Manhã } \\
\hline $2: 2$ & 51,33 Aa & 50,59 Aab & $53,33 \mathrm{Aa}$ \\
\hline $1: 3$ & $51,14 \mathrm{Aa}$ & $49,22 \mathrm{Ab}$ & $45,17 \mathrm{Bb}$ \\
\hline $3: 1$ & $54,14 \mathrm{Aa}$ & $53,57 \mathrm{Aa}$ & $55,33 \mathrm{Aa}$ \\
\hline & \multicolumn{3}{|c|}{ Consumo diário de ração - Período 2 - Manhã } \\
\hline $2: 2$ & 51,85 Aab & 51,10 Aab & $54,40 \mathrm{Aa}$ \\
\hline $1: 3$ & $51,09 \mathrm{Ab}$ & $49,95 \mathrm{ABb}$ & $47,12 \mathrm{Bb}$ \\
\hline $3: 1$ & $55,23 \mathrm{Aa}$ & $54,37 \mathrm{Aa}$ & $56,44 \mathrm{Aa}$ \\
\hline & \multicolumn{3}{|c|}{ Consumo diário de ração - Período 2 - Tarde } \\
\hline $2: 2$ & $50,76 \mathrm{Ab}$ & $51,10 \mathrm{Ab}$ & $54,40 \mathrm{Aa}$ \\
\hline $1: 3$ & $51,09 \mathrm{Aab}$ & 49,95 Aab & $47,12 \mathrm{Ab}$ \\
\hline $3: 1$ & $55,23 \mathrm{Aa}$ & $54,37 \mathrm{Aa}$ & $56,44 \mathrm{Aa}$ \\
\hline
\end{tabular}

Médias seguidas de mesma letra maiúscula (minúscula) em cada linha (coluna) não diferem entre si pelo teste de Tukey $(p>0,05)$

Durante treze semanas, em aves brancas com 27 semanas de idade, LEESON e SUMMERS (1979) ofereceram através do sistema de livre escolha (rações diferentes oferecidas simultaneamente às aves em comedouros distintos) rações contendo 13,10 e 0,47\% de cálcio. A avaliação da produção de ovos ao final do período experimental não resultou em diferença significativa em comparação às aves alimentadas com ração contendo 3,00\% de cálcio. Segundo KESHAVARZ (1986) aves submetidas a rações contendo mais que $4,50 \%$ de cálcio não apresentariam comprometimento na produção de ovos quando oferecidas por períodos inferiores a 16 semanas.

Oferecendo farinha de ostras para poedeiras semipesadas com 26 semanas de idade, MAGGIONI et al. (1996) não observaram diferença 
estatística para a produção de ovos quando compararam aves alimentadas com rações contendo 2,25 e $4,75 \%$ de cálcio, nos períodos da manhã e tarde, respectivamente, com aves alimentadas com dietas contendo $3,5 \%$ de cálcio.

KESHAVARZ $\left(1998^{\mathrm{a}}\right)$ não verificou diferença quando comparou o desempenho produtivo de aves alimentadas com rações variando de 1,5 a $4,5 \%$ de cálcio no período da manhã e 2,5 a 5,5\% de cálcio no período da tarde. Em outro estudo semelhante, KESHAVARZ $\left(1998^{\mathrm{b}}\right)$ ofereceu, para poedeiras com mais de 40 semanas de idade durante 6 semanas, dietas contendo 2,0 a 5,0\% de cálcio no período da manhã e 3,0 a 5,8\% de cálcio no período da tarde. Não foram encontradas diferenças significativas para produção diária de ovos comparando-se aves alimentadas através do sistema de fracionamento de cálcio e outras com acesso à rações contendo $3,8 \%$ de cálcio.

Em estudo mais recente, WALDROUP e HELLWIG (2000) também não encontraram diferença estatística para a produção de ovos ao compararem aves alimentadas com rações contendo $3,25 \%$ de cálcio durante todo o dia e aves submetidas ao sistema fracionado de cálcio, $3,25 \%$ no período da manhã e $6,50 \%$ no período da tarde.

Queda na produção de ovos foi observada quando houve deficiência na ingestão de cálcio por períodos superiores a 48 horas (CLUNIES et al., 1992). Nos parâmetros de peso dos ovos, massa de ovos, consumo de ração e cálcio total do dia e conversão alimentar também não foram 
observadas diferenças significativas pelos pesquisadores citados anteriormente quando o fator fracionamento de cálcio foi estudado. 
Tabela 7- Valores de consumo diário de cálcio (g/ave) por período do dia (total, manhã e tarde) de poedeiras alimentadas com diferentes fracionamentos de cálcio e granulometrias de calcário

\begin{tabular}{|c|c|c|c|c|c|c|c|c|}
\hline \multirow[t]{2}{*}{ Característica } & \multirow[t]{2}{*}{ Período } & \multicolumn{3}{|c|}{ Fracionamento de cálcio (g manhã : g tarde) } & \multicolumn{3}{|c|}{ Granulometria de calcário $^{1}$} & \multirow[t]{2}{*}{ CV (\%) } \\
\hline & & $2: 2$ & $1: 3$ & $3: 1$ & Mista & Grossa & Fina & \\
\hline Total do dia & $\begin{array}{l}1 \\
2 \\
3 \\
4 \\
\text { Geral }\end{array}$ & $\begin{array}{l}4.13 \\
4.18 \\
4.22 \\
4.20 \\
4.18 \\
\end{array}$ & $\begin{array}{l}4.21 \\
3.95 \\
4.32 \\
4.30 \\
4.19 \\
\end{array}$ & $\begin{array}{l}4.24 \\
4.43 \\
4.30 \\
4.27 \\
4.31\end{array}$ & $\begin{array}{l}4.19 \\
4.20 \\
4.26 \\
4.24 \\
4.22 \\
\end{array}$ & $\begin{array}{l}4.15 \\
4.14 \\
4.27 \\
4.25 \\
4.20 \\
\end{array}$ & $\begin{array}{l}4.23 \\
4.21 \\
4.32 \\
4.29 \\
4.26 \\
\end{array}$ & $\begin{array}{l}4.53 \\
5.08 \\
4.64 \\
4.50 \\
4.39\end{array}$ \\
\hline Período da manhã & $\begin{array}{l}1 \\
2 \\
3 \\
4 \\
\text { Geral }\end{array}$ & $\begin{array}{l}2.07 b \\
2.10 b \\
2.12 b \\
2.09 b \\
2.09 b\end{array}$ & $\begin{array}{l}0.97 c \\
0.99 c \\
1.01 c \\
0.99 c \\
0.99 c\end{array}$ & $\begin{array}{l}3.26 \mathrm{a} \\
3.32 \mathrm{a} \\
3.31 \mathrm{a} \\
3.28 \mathrm{a} \\
3.29 \mathrm{a}\end{array}$ & $\begin{array}{l}2.11 \\
2.14 \\
2.14 \\
2.12 \\
2.13 \\
\end{array}$ & $\begin{array}{l}2.07 \\
2.10 \\
2.13 \\
2.11 \\
2.10 \\
\end{array}$ & $\begin{array}{l}2.12 \\
2.17 \\
2.16 \\
2.13 \\
2.14\end{array}$ & $\begin{array}{l}4.74 \\
4.70 \\
5.00 \\
4.74 \\
4.70\end{array}$ \\
\hline Período da tarde & $\begin{array}{l}1 \\
2 \\
3 \\
4 \\
\text { Geral }\end{array}$ & $\begin{array}{l}2.06 b \\
2.08 b \\
2.10 b \\
2.11 b \\
2.09 b\end{array}$ & $\begin{array}{l}3.24 \mathrm{a} \\
2.96 \mathrm{a} \\
3.30 \mathrm{a} \\
3.31 \mathrm{a} \\
3.20 \mathrm{a}\end{array}$ & $\begin{array}{l}0.98 \mathrm{c} \\
1.11 \mathrm{c} \\
1.00 \mathrm{c} \\
1.00 \mathrm{c} \\
1.02 \mathrm{c}\end{array}$ & $\begin{array}{l}2.08 \\
2.07 \\
2.12 \\
2.12 \\
2.10\end{array}$ & $\begin{array}{l}2.08 \\
2.04 \\
2.14 \\
2.14 \\
2.10\end{array}$ & $\begin{array}{l}3.11 \\
2.04 \\
2.15 \\
2.15 \\
2.11\end{array}$ & $\begin{array}{l}6.51 \\
6.19 \\
6.56 \\
6.49 \\
5.65\end{array}$ \\
\hline
\end{tabular}

Médias seguidas de letras diferentes em cada linha e em cada fator diferem entre si pelo teste de Tukey $(p<0,05)$

1 Granulometria dos calcários $(\mathrm{mm})$ : Mista $=30 \%$ de calcário grosso e $70 \%$ de calcário fino; Grossa: entre 3,0 e 5,0 mm; Fina: inferior a 0,5 mm 
Tabela 8 - Valores de conversão alimentar (kg ração/dz de ovos e kg de ração/kg de ovo) de ovos de poedeiras alimentadas com diferentes fracionamentos de cálcio e granulometrias de calcário

\begin{tabular}{|c|c|c|c|c|c|c|c|c|}
\hline \multirow[t]{2}{*}{ Característica } & \multirow[t]{2}{*}{ Período } & \multicolumn{3}{|c|}{ Fracionamento de cálcio } & \multicolumn{3}{|c|}{ Granulometria de calcário $^{1}$} & \multirow[t]{2}{*}{$\mathrm{CV}(\%)$} \\
\hline & & $2: 2$ & $1: 3$ & $3: 1$ & Mista & Grossa & Fina & \\
\hline $\begin{array}{l}\text { Conversão alimentar } \\
\text { Kg ração / dz de ovos }\end{array}$ & $\begin{array}{l}1 \\
2^{*} \\
3 \\
4 \\
\text { Geral }\end{array}$ & $\begin{array}{l}1,43 \\
1,46 \\
1,46 \\
1,51 \\
1,47\end{array}$ & $\begin{array}{l}1,44 \\
1,39 \\
1,53 \\
1,53 \\
1,47\end{array}$ & $\begin{array}{l}1,47 \\
1,56 \\
1,52 \\
1,52 \\
1,52\end{array}$ & $\begin{array}{l}1,45 \\
1,44 \\
1,48 \\
1,52 \\
1,47\end{array}$ & $\begin{array}{l}1,46 \\
1,50 \\
1,53 \\
1,52 \\
1,50\end{array}$ & $\begin{array}{l}1,44 \\
1,47 \\
1,50 \\
1,53 \\
1,48\end{array}$ & $\begin{array}{l}5,90 \\
6,18 \\
7,31 \\
8,38 \\
5,32\end{array}$ \\
\hline $\begin{array}{l}\text { Conversão alimentar } \\
\text { g ração / g de ovo }\end{array}$ & $\begin{array}{l}1 \\
2 \\
3 \\
4 \\
\text { Geral }\end{array}$ & $\begin{array}{c}1,65 \\
1,65 \mathrm{~b} \\
1,64 \\
1,80 \\
1,68\end{array}$ & $\begin{array}{c}1,65 \\
1,57 b \\
1,69 \\
1,82 \\
1,68\end{array}$ & $\begin{array}{c}1,67 \\
1,79 a \\
1,64 \\
1,80 \\
1,72\end{array}$ & $\begin{array}{l}1,67 \\
1,68 \\
1,65 \\
1,81 \\
1,70\end{array}$ & $\begin{array}{l}1,65 \\
1,68 \\
1,65 \\
1,79 \\
1,69\end{array}$ & $\begin{array}{l}1,65 \\
1,65 \\
1,66 \\
1,83 \\
1,69\end{array}$ & $\begin{array}{l}5,80 \\
5,49 \\
6,38 \\
7,53 \\
5,18\end{array}$ \\
\hline
\end{tabular}

Médias seguidas de letras diferentes em cada linha e em cada fator diferem entre si pelo teste de Tukey $(\mathrm{p}<0,05)$

1 Granulometria dos calcários (mm): Mista $=30 \%$ de calcário grosso e $70 \%$ de calcário fino; Grossa: entre 3,0 e 5,0 mm; Fina: inferior a 0,5 mm

*Houve interação significativa e o desdobramento dos tratamentos encontra-se na Tabela 9 
Tabela 9 - Desdobramento dos tratamentos referente à característica conversão alimentar ( $\mathrm{Kg}$ ração/dz de ovo) de poedeiras alimentadas com diferentes fracionamentos de cálcio e granulometrias de calcário

\begin{tabular}{cccc}
\hline $\begin{array}{c}\text { Fracionamento de cálcio } \\
\text { (g manhã }: \mathrm{g} \text { tarde) }\end{array}$ & \multicolumn{4}{c}{ Granulometrias de Calcário } \\
& \multicolumn{4}{c}{ Conversão alimentar - Período 2} \\
$2: 2$ & $1,39 \mathrm{Ba}$ & $1,45 \mathrm{Ab}$ & $1,54 \mathrm{Aa}$ \\
$1: 3$ & $1,41 \mathrm{Aa}$ & $1,40 \mathrm{Ab}$ & $1,36 \mathrm{Ab}$ \\
$3: 1$ & $1,52 \mathrm{Aa}$ & $1,65 \mathrm{Aa}$ & $1,52 \mathrm{Aa}$ \\
\hline
\end{tabular}

Médias seguidas de mesma letra maiúscula (minúscula) em cada linha (coluna) não diferem entre si pelo teste de Tukey $(p>0,05)$

Estudando o fator granulometria das fontes de cálcio, BRISTER et al. (1981) e MARCH e AMIN (1981) não encontraram diferenças estatísticas na produção de ovos de aves brancas, com idade entre 64 e 84 semanas de idade, alimentadas com fontes de cálcio de diferentes granulometrias (não especificadas). Ao acompanhar os resultados desde o início da produção de ovos, entre 22 e 68 semanas de idade, não foi verificado por GUINOTTE e NYS $\left(1991^{\text {b }}\right)$ e KESHAVARZ et al. (1993) efeito das fontes de cálcio (calcário calcítico e farinha de ostras) e granulometrias das fontes utilizadas (mista, grossa ou fina). Mesmo em aves com idade mais avançada, 108 semanas de idade em terceiro ciclo de produção, também não têm sido encontradas diferenças significativas para a produção de ovos quando alimentadas com calcário fino ou misto (SCHEIDELER, 1998).

Considerando-se a característica de solubilidade do calcário, CHENG e COON $\left(1990^{\circ}\right)$ não encontraram diferença estatística ao compararem a produção de ovos de aves, com 36 semanas de idade, alimentadas durante 6 semanas com fontes de cálcio com solubilidades de 86 e $41 \%$, farinha de ostras moída e calcário calcítico, respectivamente. Da mesma forma, 
NAKAJIMA et al. (1995) não encontraram efeito sobre a produção de ovos de aves com mais de 50 semanas de idade alimentadas com fontes de cálcio que apresentavam as seguintes características: 14 e 16\% de solubilidade e granulometria de 1,68 e 0,50 mm, respectivamente. Também não têm sido encontrados efeitos da granulometria das fontes de cálcio sobre os parâmetros de peso dos ovos, conversão alimentar e consumo de ração.

Embora, o presente experimento não tenha avaliado os efeitos dos fatores estudados sobre outros parâmetros como variação de peso corporal, ingestão de cálcio, quantidade de cinza óssea, digestibilidade aparente dos demais nutrientes, $\mathrm{pH}$ duodenal, ileal e sangüíneo, e nível de cálcio sérico como os estudos conduzidos por MARCH e AMIN (1981), CHENG e COON (1990), KESHAVARZ et al. (1993) e SCHEIDELER (1998), sabe-se que a utilização única de fontes de cálcio com granulometria fina pode ocasionar redução na matéria orgânica e resistência à quebra dos ossos das poedeiras (CHENG e COON, 1990 e GUINOTTE e NYS, 1991).

Os resultados de consumo de ração e cálcio do presente estudo coincidem com os publicados por HOLCOMBE et al. (1975), LEESON e SUMMERS (1980), CHAH e MORAN (1985) e KESHAVARZ (1998 ${ }^{a}$ e $\left.1998^{b}\right)$. O consumo de cálcio apresentado esteve em conformidade com as recomendações de MILES (2000).

Oferecendo dietas com $0,7 \%$ de cálcio para aves em diversas faixas de idade, com a opção de rações contendo 3,0 ou $6,0 \%$ de cálcio, HOLCOMBE et al. (1975) observaram que as aves apresentaram maior 
consumo das rações contendo maiores quantidades de cálcio. LEESON e SUMMERS (1980) não encontraram efeito significativo sobre o consumo de ração total do dia de aves com a opção de se alimentarem com rações contendo 0,5 e $13,1 \%$ de cálcio. Contudo, em estudo semelhante realizado anteriormente, LEESON e SUMMERS (1979) haviam encontrado redução de $7 \%$ no consumo de ração de aves alimentadas neste sistema.

Quando houve acompanhamento do consumo de ração por período do dia, CHAH e MORAM (1985) também relataram que as aves submetidas ao sistema de cafeteria apresentaram maior consumo de ração no período da tarde.

Por outro lado, o comportamento de consumo de ração e cálcio apresentado no presente estudo para as aves alimentadas no sistema de fracionamento de cálcio 3:1 discorda dos resultados obtidos nos trabalhos relacionados ao sistema de cafeteria (HOLCOMBE et al., 1975; LEESON e SUMMERS, 1980; CHAH e MORAN,1985).

Estudos relacionados ao fracionamento de cálcio não têm apresentado o comportamento de consumo de ração e cálcio por período do dia (MAGGIONI et al., 1996 e WALDROUP e HELLWIG, 2000), mas, quando apresentados são conflitantes. KESHAVARZ $\left(1998^{\mathrm{a}}\right.$ e $\left.1998^{\mathrm{b}}\right)$ observou que aves alimentadas com maior quantidade de cálcio no período da manhã $(4,5$ a 5,5\% de cálcio) não consumiram maior quantidade de ração em relação ao período da tarde (1,5 a $2,5 \%$ de cálcio) mantendo uma proporção de consumo por período do dia de 45 e $55 \%$ para os períodos da manhã e tarde, respectivamente. 
Os dados de desempenho zootécnico obtidos no presente trabalho estão adequados aos dados que constam no manual de manejo da linhagem Babcock B-300 N.

Os dados de desempenho obtidos para poedeiras são distintos para frangos de corte onde o uso de fontes de cálcio com menor granulometria favorece o desenvolvimento das aves (McNAUGHTON, 1981 e GUINOTTE et al., 1991).

\subsection{Características de qualidade interna dos ovos}

Nas tabelas $10,11,12,13$ e 14 são apresentados os valores obtidos para peso dos ovos $(\mathrm{g})$, percentagem de albúmen (\%), percentagem de gema (\%), índice de gema e unidades Haugh, respectivamente, por horário de coleta (total, manhã e tarde). As interações observadas para cada uma destas características são apresentadas na Tabela 15 (peso dos ovos, percentagens de albúmen e gema e índice de gema) e Tabela 16 (unidades Haugh).

De maneira geral os valores obtidos para estas características estão de acordo com os valores esperados para a linhagem (Babcock B-300 N, 2000) e citados por STADELMAN e PRATT (1989).

Conforme dados apresentados na Tabela 10, o fator fracionamento de cálcio não influenciou o peso dos ovos em nenhum dos períodos experimentais $(P>0,05)$. Também não foram constatadas interações entre os 
fatores estudados para o peso dos ovos, com exceção dos ovos coletados à tarde durante o período experimental $3(P<0,05)$.

Para o fator granulometria, ovos menos pesados $(P<0,05)$ foram produzidos por aves alimentadas com calcário grosso em comparação ao calcário fino, considerando-se o valor médio total do dia (período 2), ovos produzidos no período da manhã (período 3) e tarde (período 2).

O desdobramento dos dados obtidos para peso dos ovos coletados à tarde (Tabela 15) indicou que o fracionamento de cálcio 1:3 quando combinado ao calcário grosso proporcionou ovos de menor peso $(61,21 \mathrm{~g})$ em comparação aos ovos das aves alimentadas com calcário fino (65,50 g). Para as aves submetidas aos sistemas de fracionamento de cálcio 2:2 e 3:1, o uso de calcário grosso resultou em ovos de maior peso $(66,78$ e 70,00g) quando comparados ao uso de calcário fino (62,30 e 62,34g).

Considerando-se o período total do experimento para os ovos coletados no período da tarde, o sistema de fracionamento 3:1 resultou em ovos com peso inferior $(P<0,05)$ em relação aos demais tratamentos.

A percentagem de albúmen não foi influenciada $(P>0,05)$ pelos fatores estudados (Tabela 11). Porém, nos ovos coletados no período da manhã ocorreu interação no período experimental 2. Também foi observada interação no período experimental 4 e diferença estatística quando foi considerado o período total do experimento para os ovos coletados no período da tarde.

Durante o período experimental 2 (Tabela 15), as aves alimentadas pelo sistema de fracionamento de cálcio 3:1 produziram ovos com menor 
percentual de albúmen $(55,58 \%)$ em comparação às que foram submetidas ao sistema 2:2 (58,57\%) quando alimentadas com calcário fino. Além disso, foram encontradas menores percentagens de albúmen para os ovos de aves submetidas ao sistema de fracionamento de cálcio 1:3 quando associado ao calcário grosso $(54,83 \%)$ em comparação aos demais calcários, misto $(58,30 \%)$ e fino $(58,41 \%)$.

A interação encontrada $(P<0,05)$ no período experimental 4 (Tabela 15), para os ovos produzidos à tarde, resultou em menor percentagem de albúmen dos ovos das aves alimentadas pelo sistema de fracionamento de cálcio 2:2 com uso de calcário misto $(51,92 \%)$ em comparação ao calcário grosso $(56,80 \%)$. No fracionamento $1: 3$ a diferença ocorreu entre o uso de calcário grosso e fino (52,62 e 58,01\%, respectivamente). Quando o sistema de fracionamento de cálcio adotado foi o 3:1, as aves alimentadas com calcário misto produziram ovos com maior percentual de albúmen (55,55 \%) em comparação aos demais calcários (48,52 e 50,28\%).

A percentagem de gema foi influenciada pelos fatores estudados (Tabela 12). Verificou-se diferenças significativas para o fator fracionamento de cálcio no terceiro período experimental para os valores médios total do dia e para o fator granulometria no segundo período experimental no período da manhã. Interações entre os fatores ocorreram em todo o período experimental para os valores total do dia e período da tarde, cujo desdobramentos encontram-se na Tabela 15. Outra interação foi observada durante o quarto período experimental para os ovos produzidos no período da tarde. 
Durante o terceiro período experimental, aves submetidas ao sistema de fracionamento de cálcio 3:1 produziram ovos com maior percentual de gema $(31,81 \%)$ em comparação ao esquema de fracionamento 2:2 $(27,94 \%)$, quando a análise considerou todo os ovos produzidos durante o dia.

Analisando a média do dia ao final de todo período experimental (Tabela 15), menor percentual de gema $(28,24 \%)$ foi encontrado em ovos de aves alimentadas com calcário grosso no sistema de fracionamento de cálcio 3:1 em comparação às demais granulometrias (31,03 e 31,77\%). O uso de calcário misto ou fino resultou em menor percentual de gema $(27,57$ e $28,96 \%$ ) quando oferecidos através do sistema de fracionamento de cálcio 2:2 em comparação ao sistema 3:1 (31,03 e 31,77\%).

Para os ovos produzidos no período da tarde, durante o quarto período experimental (Tabela 15), submetidos ao fracionamento de cálcio $2: 2$, o uso de calcário misto resultou em menor percentual de gema $(27,90 \%)$ quando comparado ao calcário fino (32,23\%). Fracionando o cálcio em 3:1, o uso de calcário fino proporcionou maior percentual de gema $(35,88 \%)$ comparativamente ao calcário misto ou grosso, 31,27 e 31,63\%. Também, com a disponibilização do calcário misto, as aves alimentadas através do fracionamento 2:2 produziram ovos com menor percentual de gema $(27,90 \%)$ em comparação às aves submetidas ao sistema $3: 1$ (31,03\%). Somado a isto, o uso de calcário fino associado a este mesmo esquema de fracionamento resultou em ovos com maior percentual de gema $(35,88 \%)$ comparando-se ao 2:2 e 1:3 (32,23 e 31,59\%), respectivamente. 
Neste mesmo período de coleta (tarde) e considerando o período total do experimento (Tabela 15), menor percentual de gema foi encontrado nos ovos de aves alimentadas com calcário grosso $(28,74 \%)$ em relação aos calcários misto e fino (34,66 e 33,32\%, respectivamente) quando o sistema de fracionamento $3: 1$ foi adotado. Somado a isto, maiores percentuais de gema nos ovos foram encontrados quando este sistema esteve associado aos calcários misto e fino.

$\mathrm{Na}$ Tabela 13 são apresentados os valores obtidos para índice de gema. As respectivas interações $(P<0,05)$ e seus desdobramentos são relacionados na Tabela 15.

Durante o período experimental 2, quando a média de resultados dos ovos coletados no dia foi analisada, fracionando o cálcio em 3:1 resultou em menor índice de gema $(0,38)$ em relação ao sistema 2:2 $(0,39)$. Entretanto, no quarto período experimental, analisando-se os ovos postos somente no período matutino, o sistema de fracionamento 3:1 resultou em menor índice de gema $(0,40)$ quando comparado ao esquema $2: 2(0,42)$. Para os ovos coletados no período da tarde, a diferença observada está associada à granulometria dos calcários. Menores índices de gema foram observados em ovos de aves alimentadas com calcário misto $(0,39)$ em comparação ao uso de calcário grosso $(0,41)$.

No período da manhã (Tabela 15), durante o primeiro período experimental, o índice de gema dos ovos de aves alimentadas com calcário grosso foi superior $(0,40)$ ao uso do calcário misto $(0,38)$ considerando-se o fracionamento de cálcio 3:1. Com o uso de calcário grosso este mesmo 
fracionamento foi superior ao sistema 2:2 $(0,38)$. Para o calcário fino, mostrou-se benéfico o sistema 1:3 em comparação ao esquema 2:2 (0,38 e 0,36 , respectivamente).

Analisando todos os ovos coletados durante o período experimental 4, o fracionamento 2:2 associado ao calcário misto teve índice de gema inferior $(0,40)$ aos demais calcários $(0,42$ e 0,42$)$, enquanto o fracionamento 2:2 associado ao calcário fino foi superior $(0,42)$ às demais alternativas propostas $(0,40$ e 0,39 respectivamente).

$\mathrm{Na}$ Tabela 14 são apresentados os valores obtidos para unidades Haugh. As diferenças estatísticas e interações $(P<0,05)$ foram observadas quando as médias obtidas foram analisadas por período experimental ou momento da coleta dos ovos.

Para o fator fracionamento de cálcio ocorreram diferenças significativas $(P<0,05)$ para os ovos coletados no terceiro período experimental e total geral do experimento quando apenas os ovos produzidos no período vespertino foram considerados.

Para o fator granulometria dos calcários, as diferenças estatísticas $(P<0,05)$ foram detectadas quando foram analisados a média total dos ovos coletados no dia (período 2) e ovos coletados no período da tarde (períodos 1 e 3).

As interações $(P<0,05)$ são observadas durante os três primeiros períodos experimentais quando analisou-se os dados obtidos com os ovos coletados no período da manhã e os respectivos desdobramentos encontram-se na Tabela 16. 
Tabela 10 - Valores de peso dos ovos (g) por período do dia (total, manhã e tarde) de poedeiras alimentadas com diferentes fracionamentos de cálcio e granulometrias de calcário

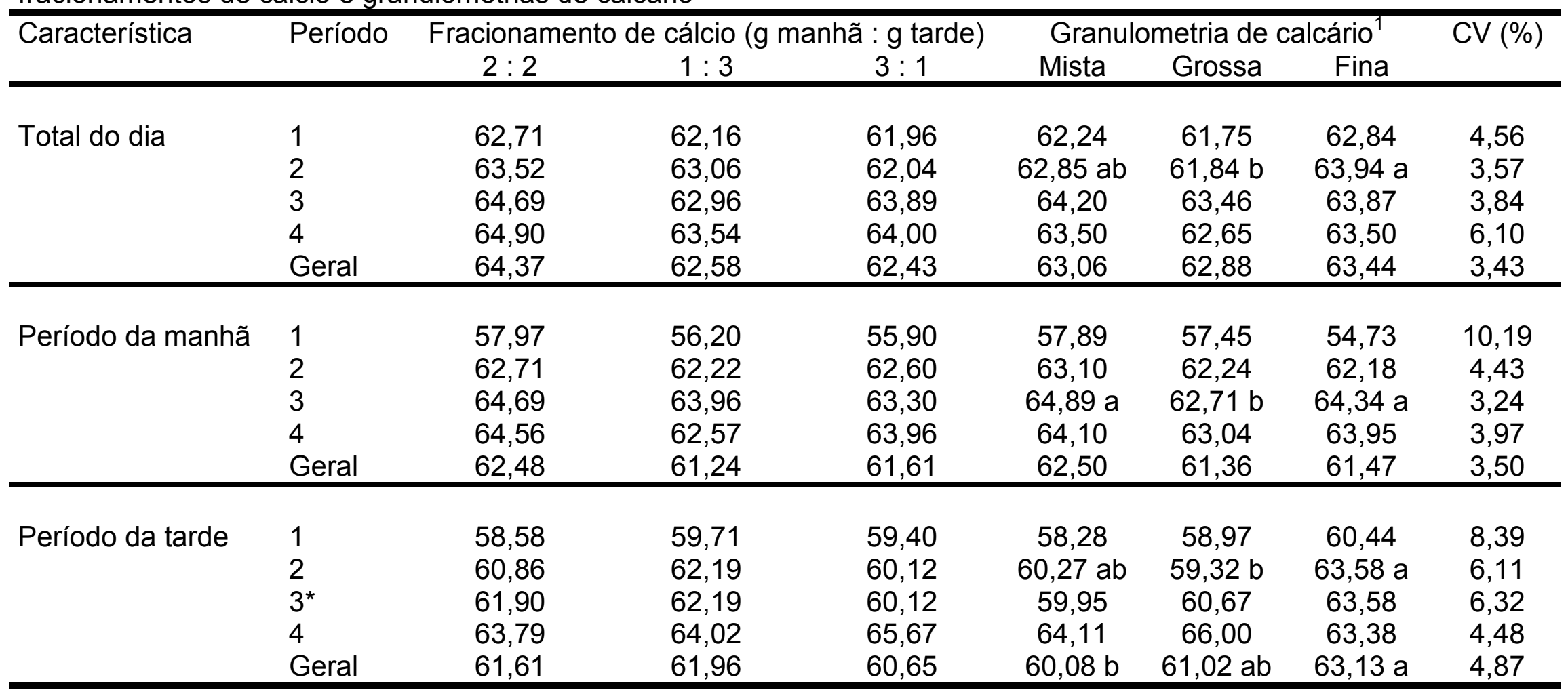

Médias seguidas de letras diferentes em cada linha e em cada fator diferem entre si pelo teste de Tukey $(p<0,05)$

1 Granulometria $(\mathrm{mm})$ dos calcários: Mista = 30\% de calcário grosso e 70\% de calcário fino; Grossa: entre 3,0 e 5,0 mm; Fina: inferior a 0,5 mm *Houve interação significativa e o desdobramento dos tratamentos encontra-se na Tabela 15 
Tabela 11 - Valores de percentagem de albúmen dos ovos (\%) por período do dia (total, manhã e tarde) de poedeiras alimentadas com diferentes fracionamentos de cálcio e granulometrias de calcário

\begin{tabular}{|c|c|c|c|c|c|c|c|c|}
\hline \multirow[t]{2}{*}{ Característica } & \multirow[t]{2}{*}{ Período } & \multicolumn{3}{|c|}{ Fracionamento de cálcio (g manhã : g tarde) } & \multicolumn{3}{|c|}{ Granulometria de calcário $^{1}$} & \multirow[t]{2}{*}{$\mathrm{CV}(\%)$} \\
\hline & & $2: 2$ & $1: 3$ & $3: 1$ & Mista & Grossa & Fina & \\
\hline Total do dia & $\begin{array}{l}1 \\
2 \\
3 \\
4 \\
\text { Geral } \\
\end{array}$ & $\begin{array}{l}58,38 \\
57,98 \\
57,30 \\
56,95 \\
57,65 \\
\end{array}$ & $\begin{array}{l}57,16 \\
57,42 \\
56,35 \\
59,25 \\
57,55 \\
\end{array}$ & $\begin{array}{l}58,09 \\
56,72 \\
52,08 \\
56,69 \\
55,92 \\
\end{array}$ & $\begin{array}{l}58,87 \\
57,86 \\
54,94 \\
57,47 \\
57,28 \\
\end{array}$ & $\begin{array}{l}57,42 \\
56,90 \\
56,67 \\
57,26 \\
57,09 \\
\end{array}$ & $\begin{array}{l}57,33 \\
57,36 \\
54,11 \\
58,16 \\
56,74\end{array}$ & $\begin{array}{l}3,69 \\
3,43 \\
7,90 \\
8,28 \\
3,56 \\
\end{array}$ \\
\hline Período da manhã & $\begin{array}{l}1 \\
2^{*} \\
3 \\
4 \\
\text { Geral }\end{array}$ & $\begin{array}{l}59,05 \\
57,89 \\
57,29 \\
58,70 \\
58,33\end{array}$ & $\begin{array}{l}56,64 \\
57,18 \\
56,19 \\
61,05 \\
57,76 \\
\end{array}$ & $\begin{array}{l}58,42 \\
56,46 \\
55,97 \\
59,44 \\
57,58\end{array}$ & $\begin{array}{l}59,41 \\
57,50 \\
56,76 \\
60,09 \\
58,54\end{array}$ & $\begin{array}{l}57,20 \\
56,51 \\
56,94 \\
59,13 \\
57,45\end{array}$ & $\begin{array}{l}57,50 \\
57,52 \\
55,76 \\
59,97 \\
57,69\end{array}$ & $\begin{array}{c}5,18 \\
3,24 \\
4,89 \\
12,28 \\
3,90 \\
\end{array}$ \\
\hline Período da tarde & $\begin{array}{l}1 \\
2 \\
3 \\
4^{*} \\
\text { Geral }\end{array}$ & $\begin{array}{c}57,35 \\
57,66 \\
56,64 \\
54,05 \\
56,42 \text { a }\end{array}$ & $\begin{array}{c}57,68 \\
57,68 \\
56,89 \\
54,99 \\
56,99 \text { a }\end{array}$ & $\begin{array}{c}56,83 \\
56,83 \\
56,58 \\
51,45 \\
52,14 \text { b }\end{array}$ & $\begin{array}{l}58,15 \\
58,47 \\
57,96 \\
53,93 \\
55,15\end{array}$ & $\begin{array}{l}56,89 \\
56,87 \\
55,85 \\
52,64 \\
55,36\end{array}$ & $\begin{array}{l}56,83 \\
56,83 \\
56,30 \\
53,91 \\
55,04\end{array}$ & $\begin{array}{l}5,33 \\
5,29 \\
3,31 \\
4,11 \\
4,96\end{array}$ \\
\hline
\end{tabular}

Médias seguidas de letras diferentes em cada linha e em cada fator diferem entre si pelo teste de Tukey $(p<0,05)$

1 Granulometria $(\mathrm{mm})$ dos calcários: Mista $=30 \%$ de calcário grosso e $70 \%$ de calcário fino; Grossa: entre 3,0 e 5,0 mm; Fina: inferior a 0,5 mm

* Houve interação significativa e o desdobramento dos tratamentos encontra-se na Tabela 15 
Tabela 12 - Valores de percentagem de gema dos ovos (\%) por período do dia (total, manhã e tarde) de poedeiras alimentadas com diferentes fracionamentos de cálcio e granulometrias de calcário

\begin{tabular}{|c|c|c|c|c|c|c|c|c|}
\hline \multirow[t]{2}{*}{ Característica } & \multirow[t]{2}{*}{ Período } & \multicolumn{3}{|c|}{ Fracionamento de cálcio (g manhã : g tarde) } & \multicolumn{3}{|c|}{ Granulometria de calcário $^{1}$} & \multirow[t]{2}{*}{$\mathrm{CV}(\%)$} \\
\hline & & $2: 2$ & $1: 3$ & $3: 1$ & Mista & Grossa & Fina & \\
\hline Total do dia & $\begin{array}{l}1 \\
2 \\
3 \\
4 \\
\text { Geral }^{*} \\
\end{array}$ & $\begin{array}{c}27,03 \\
27,36 \\
27,94 \text { b } \\
32,26 \\
28,65 \\
\end{array}$ & $\begin{array}{c}27,56 \\
27,80 \\
28,52 \mathrm{ab} \\
34,05 \\
29,48\end{array}$ & $\begin{array}{c}27,80 \\
27,97 \\
31,81 \text { a } \\
34,21 \\
30,35 \\
\end{array}$ & $\begin{array}{l}27,36 \\
27,40 \\
29,80 \\
32,32 \\
29,22 \\
\end{array}$ & $\begin{array}{l}27,47 \\
27,67 \\
28,11 \\
33,18 \\
29,01 \\
\end{array}$ & $\begin{array}{l}27,56 \\
28,07 \\
30,34 \\
35,01 \\
30,24 \\
\end{array}$ & $\begin{array}{c}3,74 \\
4,22 \\
13,12 \\
10,57 \\
5,02 \\
\end{array}$ \\
\hline Período da manhã & $\begin{array}{l}1 \\
2 \\
3 \\
4 \\
\text { Geral }\end{array}$ & $\begin{array}{l}27,49 \\
27,77 \\
28,06 \\
28,74 \\
28,27\end{array}$ & $\begin{array}{l}28,06 \\
28,58 \\
29,04 \\
29,54 \\
29,05 \\
\end{array}$ & $\begin{array}{l}27,77 \\
28,18 \\
28,05 \\
30,38 \\
28,76 \\
\end{array}$ & $\begin{array}{c}27,76 \\
27,59 \text { b } \\
27,83 \\
28,65 \\
28,20\end{array}$ & $\begin{array}{c}27,62 \\
28,20 \mathrm{ab} \\
28,24 \\
29,28 \\
28,50\end{array}$ & $\begin{array}{c}27,93 \\
28,74 \text { a } \\
29,07 \\
30,74 \\
29,37\end{array}$ & $\begin{array}{c}5,33 \\
4,44 \\
5,42 \\
13,65 \\
4,65 \\
\end{array}$ \\
\hline Período da tarde & $\begin{array}{l}1 \\
2 \\
3 \\
4^{*} \\
\text { Geral }^{*}\end{array}$ & $\begin{array}{c}26,42 \\
26,60 \\
27,16 \\
30,32 \\
27,64 \text { b }\end{array}$ & $\begin{array}{r}26,97 \\
26,97 \\
27,33 \\
32,00 \\
28,10 \mathrm{~b}\end{array}$ & $\begin{array}{c}28,08 \\
28,08 \\
27,34 \\
32,93 \\
32,24 \text { a }\end{array}$ & $\begin{array}{c}26,92 \\
27,12 \\
27,10 \\
30,78 \text { b } \\
29,85\end{array}$ & $\begin{array}{c}27,40 \\
27,38 \\
27,85 \\
31,24 \mathrm{ab} \\
28,56\end{array}$ & $\begin{array}{c}27,15 \\
27,15 \\
26,88 \\
33,23 \text { a } \\
29,57\end{array}$ & $\begin{array}{l}6,42 \\
6,11 \\
3,99 \\
6,09 \\
7,75\end{array}$ \\
\hline
\end{tabular}

Médias seguidas de letras diferentes em cada linha e em cada fator diferem entre si pelo teste de Tukey $(p<0,05)$

1 Granulometria dos calcários $(\mathrm{mm})$ : Mista $=30 \%$ de calcário grosso e $70 \%$ de calcário fino; Grossa: entre 3,0 e 5,0 mm; Fina: inferior a 0,5 mm

* Houve interação significativa e o desdobramento dos tratamentos encontra-se na Tabela 15 
Tabela 13 - Valores de índice de gema dos ovos por período do dia (total, manhã e tarde) de poedeiras alimentadas com diferentes fracionamentos de cálcio e granulometrias de calcário

\begin{tabular}{|c|c|c|c|c|c|c|c|c|}
\hline \multirow[t]{2}{*}{ Característica } & \multirow[t]{2}{*}{ Período } & \multicolumn{3}{|c|}{ Fracionamento de cálcio (g manhã : g tarde) } & \multicolumn{3}{|c|}{ Granulometria de calcário $^{1}$} & \multirow[t]{2}{*}{$\mathrm{CV}(\%)$} \\
\hline & & $2: 2$ & $1: 3$ & $3: 1$ & Mista & Grossa & Fina & \\
\hline Total do dia & $\begin{array}{l}1 \\
2 \\
3 \\
4^{*} \\
\text { Geral } \\
\end{array}$ & $\begin{array}{c}0,37 \\
0,39 \text { a } \\
0,41 \\
0,42 \\
0,40 \\
\end{array}$ & $\begin{array}{c}0,37 \\
0,38 \mathrm{~b} \\
0,42 \\
0,41 \\
0,39 \\
\end{array}$ & $\begin{array}{c}0,38 \\
0,38 \text { ab } \\
0,41 \\
0,40 \\
0,39\end{array}$ & $\begin{array}{l}0,37 \\
0,38 \\
0,41 \\
0,40 \\
0,39 \\
\end{array}$ & $\begin{array}{l}0,38 \\
0,38 \\
0,41 \\
0,41 \\
0,40 \\
\end{array}$ & $\begin{array}{l}0,38 \\
0,39 \\
0,41 \\
0,40 \\
0,40 \\
\end{array}$ & $\begin{array}{l}3,17 \\
3,73 \\
4,46 \\
3,18 \\
2,12 \\
\end{array}$ \\
\hline Período da manhã & $\begin{array}{l}1^{*} \\
2 \\
3 \\
4 \\
\text { Geral }\end{array}$ & $\begin{array}{c}0,37 \\
0,39 \\
0,41 \\
0,42 \text { a } \\
0,40\end{array}$ & $\begin{array}{c}0,38 \\
0,39 \\
0,42 \\
0,41 \mathrm{ab} \\
0,40\end{array}$ & $\begin{array}{c}0,38 \\
0,39 \\
0,41 \\
0,40 \mathrm{~b} \\
0,40\end{array}$ & $\begin{array}{l}0,37 \\
0,39 \\
0,41 \\
0,41 \\
0,40\end{array}$ & $\begin{array}{l}0,38 \\
0,39 \\
0,41 \\
0,41 \\
0,40\end{array}$ & $\begin{array}{l}0,37 \\
0,39 \\
0,41 \\
0,41 \\
0,40\end{array}$ & $\begin{array}{l}3,03 \\
4,51 \\
4,54 \\
4,35 \\
2,31 \\
\end{array}$ \\
\hline Período da tarde & $\begin{array}{l}1 \\
2 \\
3 \\
4 \\
\text { Geral }\end{array}$ & $\begin{array}{l}0,37 \\
0,38 \\
0,39 \\
0,40 \\
0,39\end{array}$ & $\begin{array}{l}0,36 \\
0,36 \\
0,40 \\
0,41 \\
0,38\end{array}$ & $\begin{array}{l}0,38 \\
0,38 \\
0,40 \\
0,40 \\
0,39\end{array}$ & $\begin{array}{c}0,36 \\
0,37 \\
0,39 \mathrm{~b} \\
0,40 \\
0,38\end{array}$ & $\begin{array}{c}0,37 \\
0,37 \\
0,41 \text { a } \\
0,41 \\
0,39\end{array}$ & $\begin{array}{c}0,38 \\
0,38 \\
0,40 \mathrm{ab} \\
0,40 \\
0,39\end{array}$ & $\begin{array}{l}6,14 \\
5,72 \\
3,52 \\
5,22 \\
4,27\end{array}$ \\
\hline
\end{tabular}

Médias seguidas de letras diferentes em cada linha e em cada fator diferem entre si pelo teste de Tukey $(p<0,05)$

1 Granulometria dos calcários $(\mathrm{mm})$ : Mista $=30 \%$ de calcário grosso e 70\% de calcário fino; Grossa: entre 3,0 e 5,0 mm; Fina: inferior a 0,5 mm

* Houve interação significativa e o desdobramento dos tratamentos encontra-se na Tabela 15 
Tabela 14 - Valores de unidades Haugh dos ovos por período do dia (total, manhã e tarde) de poedeiras alimentadas com diferentes fracionamentos de cálcio e granulometrias de calcário

\begin{tabular}{|c|c|c|c|c|c|c|c|c|}
\hline \multirow[t]{2}{*}{ Característica } & \multirow[t]{2}{*}{ Período } & \multicolumn{3}{|c|}{ Fracionamento de cálcio (g manhã : g tarde) } & \multicolumn{3}{|c|}{ Granulometria de calcário $^{1}$} & \multirow[t]{2}{*}{ CV (\%) } \\
\hline & & $2: 2$ & $1: 3$ & $3: 1$ & Mista & Grossa & Fina & \\
\hline Total do dia & $\begin{array}{l}1 \\
2 \\
3 \\
4 \\
\text { Geral } \\
\end{array}$ & $\begin{array}{l}98,48 \\
97,43 \\
98,50 \\
98,00 \\
97,01 \\
\end{array}$ & $\begin{array}{l}98,68 \\
98,08 \\
96,73 \\
96,86 \\
97,41 \\
\end{array}$ & $\begin{array}{l}97,99 \\
98,79 \\
96,18 \\
95,20 \\
97,21 \\
\end{array}$ & $\begin{array}{c}99,13 \\
97,70 \mathrm{ab} \\
98,53 \\
98,07 \\
98,36\end{array}$ & $\begin{array}{c}96,86 \\
96,42 \text { b } \\
96,25 \\
95,85 \\
96,32 \\
\end{array}$ & $\begin{array}{c}99,16 \\
100,17 \text { a } \\
96,63 \\
96,14 \\
97,03\end{array}$ & $\begin{array}{l}3,12 \\
3,14 \\
4,49 \\
4,68 \\
5,47\end{array}$ \\
\hline Período da manhã & $\begin{array}{l}1^{*} \\
2^{*} \\
3^{*} \\
4 \\
\text { Geral }\end{array}$ & $\begin{array}{c}97,82 \\
100,38 \\
99,92 \\
98,55 \\
99,34\end{array}$ & $\begin{array}{l}98,92 \\
99,14 \\
98,69 \\
97,33 \\
98,52\end{array}$ & $\begin{array}{l}98,39 \\
98,68 \\
97,26 \\
94,64 \\
97,24\end{array}$ & $\begin{array}{c}98,38 \\
98,69 \\
100,42 \\
98,49 \\
99,00\end{array}$ & $\begin{array}{l}97,93 \\
99,30 \\
97,98 \\
96,30 \\
98,04\end{array}$ & $\begin{array}{c}98,82 \\
100,22 \\
97,47 \\
95,73 \\
98,06\end{array}$ & $\begin{array}{l}3,58 \\
2,76 \\
3,73 \\
4,86 \\
2,41\end{array}$ \\
\hline Período da tarde & $\begin{array}{l}1 \\
2 \\
3 \\
4 \\
\text { Geral }\end{array}$ & $\begin{array}{c}98,17 \\
97,31 \\
92,84 \mathrm{~b} \\
91,68 \\
97,50 \mathrm{a}\end{array}$ & $\begin{array}{c}97,00 \\
95,43 \\
97,00 \mathrm{ab} \\
91,20 \\
93,05 \mathrm{~b}\end{array}$ & $\begin{array}{c}98.79 \\
97,04 \\
98,79 \text { a } \\
93,79 \\
98,88 \text { a }\end{array}$ & $\begin{array}{c}100,12 \mathrm{a} \\
96,90 \\
97,31 \mathrm{a} \\
93,37 \\
95,92\end{array}$ & $\begin{array}{c}93,46 \mathrm{~b} \\
95,34 \\
90,96 \mathrm{~b} \\
92,27 \\
95,88\end{array}$ & $\begin{array}{c}100,37 \text { a } \\
97,54 \\
100,37 \text { a } \\
91,03 \\
97,64\end{array}$ & $\begin{array}{l}4,88 \\
5,60 \\
4,80 \\
5,64 \\
3,81\end{array}$ \\
\hline
\end{tabular}


Tabela 15 - Desdobramento dos tratamentos referentes às características peso (g), percentagens de albúmen e gema (\%) e índice de gema dos ovos de poedeiras alimentadas com diferentes fracionamentos de cálcio e granulometrias de calcário

\begin{tabular}{|c|c|c|c|}
\hline \multirow{2}{*}{$\begin{array}{l}\text { Fracionamento de cálcio } \\
\text { (g manhã : g tarde) }\end{array}$} & \multicolumn{3}{|c|}{ Granulometrias de Calcário } \\
\hline & Mista & Grossa & Fina \\
\hline & \multicolumn{3}{|c|}{ Peso dos ovos - Período 3 - Tarde } \\
\hline $2: 2$ & $62,23 \mathrm{Ba}$ & $66,78 \mathrm{Aab}$ & $62,30 \mathrm{Ba}$ \\
\hline $1: 3$ & $65,35 \mathrm{Aa}$ & $61,21 \mathrm{Bb}$ & $65,50 \mathrm{Aa}$ \\
\hline \multirow[t]{2}{*}{$3: 1$} & $64,68 \mathrm{ABa}$ & $70,00 \mathrm{Aa}$ & $62,34 \mathrm{Ba}$ \\
\hline & \multicolumn{3}{|c|}{ Percentagem de albúmen - Período 2 - Manhã } \\
\hline $2: 2$ & $57,44 \mathrm{Aa}$ & $57,67 \mathrm{Aa}$ & $58,57 \mathrm{Aa}$ \\
\hline $1: 3$ & $58,30 \mathrm{Aa}$ & $54,83 \mathrm{Ba}$ & $58,41 \mathrm{Aab}$ \\
\hline \multirow[t]{2}{*}{$3: 1$} & $56,77 \mathrm{Aa}$ & $57,03 \mathrm{Aa}$ & $55,58 \mathrm{Ab}$ \\
\hline & \multicolumn{3}{|c|}{ Percentagem de albúmen - Período 4 - Tarde } \\
\hline $2: 2$ & $51,92 \mathrm{Ba}$ & $56,80 \mathrm{Aa}$ & $53,43 \mathrm{ABa}$ \\
\hline $1: 3$ & $54,33 \mathrm{ABa}$ & $52,62 \mathrm{Ba}$ & $58,01 \mathrm{Aa}$ \\
\hline \multirow[t]{2}{*}{$3: 1$} & $55,55 \mathrm{Aa}$ & $48,52 \mathrm{Ba}$ & $50,28 \mathrm{Ba}$ \\
\hline & \multicolumn{3}{|c|}{ Percentagem de gema - Geral - Dia } \\
\hline $2: 2$ & $27,57 \mathrm{Ab}$ & $29,41 \mathrm{Aa}$ & $28,96 \mathrm{Ab}$ \\
\hline $1: 3$ & 29,06 Aab & $29,38 \mathrm{Aa}$ & $30,00 \mathrm{Aab}$ \\
\hline \multirow[t]{2}{*}{$3: 1$} & $31,03 \mathrm{Aa}$ & $28,24 \mathrm{Ba}$ & $31,77 \mathrm{Aa}$ \\
\hline & \multicolumn{3}{|c|}{ Percentagem de gema - Período 4 - Tarde } \\
\hline $2: 2$ & $27,90 \mathrm{Bb}$ & $30,84 \mathrm{ABa}$ & $32,23 \mathrm{Ab}$ \\
\hline $1: 3$ & $33,16 \mathrm{Aa}$ & $31,24 \mathrm{Aa}$ & $31,59 \mathrm{Ab}$ \\
\hline \multirow[t]{2}{*}{$3: 1$} & $31,27 \mathrm{Bab}$ & $31,63 \mathrm{Ba}$ & $35,88 \mathrm{Aa}$ \\
\hline & \multicolumn{3}{|c|}{ Percentagem de gema - Total - Tarde } \\
\hline $2: 2$ & $26,23 \mathrm{Ab}$ & $28,34 \mathrm{Aa}$ & $28,34 \mathrm{Ab}$ \\
\hline $1: 3$ & $28,65 \mathrm{Ab}$ & $28,61 \mathrm{Aa}$ & $27,05 \mathrm{Ab}$ \\
\hline \multirow[t]{2}{*}{$3: 1$} & $34,66 \mathrm{Aa}$ & $28,74 \mathrm{Ba}$ & 33,32 Aa \\
\hline & \multicolumn{3}{|c|}{ Índice de gema - Período 1 - Manhã } \\
\hline $2: 2$ & $0,38 \mathrm{Aa}$ & $0,38 \mathrm{Ab}$ & $0,36 \mathrm{Ab}$ \\
\hline $1: 3$ & $0,37 \mathrm{Aa}$ & $0,38 \mathrm{Aab}$ & $0,38 \mathrm{Aa}$ \\
\hline \multirow[t]{2}{*}{$3: 1$} & $0,38 \mathrm{Ba}$ & $0,40 \mathrm{Aa}$ & $0,38 \mathrm{ABab}$ \\
\hline & \multicolumn{3}{|c|}{ Índice de gema - Período 4 - Dia } \\
\hline $2: 2$ & $0,40 \mathrm{Ba}$ & $0,42 \mathrm{Aa}$ & $0,42 \mathrm{Aa}$ \\
\hline $1: 3$ & $0,41 \mathrm{Aa}$ & $0,41 \mathrm{Aa}$ & $0,40 \mathrm{Ab}$ \\
\hline $3: 1$ & $0,40 \mathrm{Aa}$ & $0,41 \mathrm{Aa}$ & $0,39 \mathrm{Ab}$ \\
\hline
\end{tabular}

Médias seguidas de mesma letra maiúscula (minúscula) em cada linha (coluna) não diferem entre si pelo teste de Tukey $(p>0,05)$ 
Tabela 16 - Desdobramento dos tratamentos referentes à característica de unidades Haugh dos ovos de poedeiras alimentadas com diferentes fracionamentos de cálcio e granulometrias de calcário

\begin{tabular}{|c|c|c|c|}
\hline \multirow{2}{*}{$\begin{array}{l}\text { Fracionamento de cálcio } \\
\text { (g manhã : g tarde) }\end{array}$} & \multicolumn{3}{|c|}{ Granulometrias de Calcário } \\
\hline & Mista & Grossa & Fina \\
\hline & \multicolumn{3}{|c|}{ Conversão alimentar - Período 2} \\
\hline $2: 2$ & 1,39 Ba & $1,45 \mathrm{Ab}$ & 1,54 Aa \\
\hline $1: 3$ & $1,41 \mathrm{Aa}$ & $1,40 \mathrm{Ab}$ & $1,36 \mathrm{Ab}$ \\
\hline $3: 1$ & $1,52 \mathrm{Aa}$ & $1,65 \mathrm{Aa}$ & $1,52 \mathrm{Aa}$ \\
\hline & \multicolumn{3}{|c|}{ Unidades Haugh - Período 2 - Manhã } \\
\hline $2: 2$ & $101,07 \mathrm{Aa}$ & $100,35 \mathrm{Aa}$ & $99,74 \mathrm{Aa}$ \\
\hline $1: 3$ & 99,56 Aab & $97,48 \mathrm{Aa}$ & $100,36 \mathrm{Aa}$ \\
\hline $3: 1$ & $95,43 \mathrm{Bb}$ & $100,06 \mathrm{Aa}$ & $100,55 \mathrm{Aa}$ \\
\hline & \multicolumn{3}{|c|}{ Unidades Haugh - Período 3 - Manhã } \\
\hline $2: 2$ & $101,78 \mathrm{Aa}$ & $101,48 \mathrm{Aa}$ & $96,49 \mathrm{Aa}$ \\
\hline $1: 3$ & $97,91 \mathrm{Aa}$ & $98,29 \mathrm{Aab}$ & $99,86 \mathrm{Aa}$ \\
\hline $3: 1$ & $101,57 \mathrm{Aa}$ & $94,16 \mathrm{Bb}$ & $96,03 \mathrm{ABa}$ \\
\hline & \multicolumn{3}{|c|}{ Unidades Haugh - Período 1 - Manhã } \\
\hline $2: 2$ & $100,69 \mathrm{Aa}$ & $94,58 \mathrm{Ba}$ & $98,20 \mathrm{Aba}$ \\
\hline $1: 3$ & $97,34 \mathrm{Aa}$ & $99,22 \mathrm{Aa}$ & $100,19 \mathrm{Aa}$ \\
\hline $3: 1$ & $97,12 \mathrm{Aa}$ & 99,99 Aa & $98,06 \mathrm{Aa}$ \\
\hline
\end{tabular}

Médias seguidas de mesma letra maiúscula (minúscula) em cada linha (coluna) não diferem entre si pelo teste de Tukey $(p>0,05)$

A inexistência do efeito do fator fracionamento sobre o peso dos ovos é compartilhada pelos trabalhos de MAGGIONI et al. (1996), KESHAVARZ (1998 a ${ }^{a} 1998^{b}$ ) e WALDROUP e HELLWIG (2000). Quando considerado o fator granulometria das fontes de cálcio, esta mesma situação pôde ser constatada nos trabalhos de BRISTER et al. (1981), MARCH e AMIN (1981), CHENG e COON (1990), GUINOTTE e NYS (1991) e NAKAJIMA et al. (1995). Além disso, não são encontradas citações que relacionem a solubilidade das fontes de cálcio e peso dos ovos.

Porém, a diferença encontrada para os períodos supra citados assemelha-se aos resultados obtidos por KESHAVARZ et al. (1993) onde os 
ovos de aves alimentadas apenas com calcário fino foram mais leves em comparação aos ovos de aves alimentadas com uma mistura de calcário grosso e fino.

\subsection{Características de qualidade externa dos ovos}

Os valores obtidos para os parâmetros de qualidade externa dos ovos são apresentados nas Tabelas 17, 18 e 19, referindo-se à percentagem de casca, espessura da casca e densidade aparente dos ovos, respectivamente.

No geral, não houve efeito nem interação $(P>0,05)$ dos fatores estudados sobre estes parâmetros. Entretanto, foram observadas diferenças em períodos experimentais isoladamente ou quando os ovos de um determinado período de coleta foram analisados separadamente.

Os resultados obtidos para a percentagem de casca não apresentam efeito nem interação $(P>0,05)$ pelos fatores estudados quando foram considerados todos os ovos coletados durante o dia (Tabela 17). Porém, através da análise dos ovos coletados no período da manhã, houve diferença significativa $(P<0,05)$. No período experimental 3 , as aves alimentadas somente com calcário fino produziram ovos com menor percentual de casca quando comparado quando comparados às demais granulometrias. Além disso, durante o último período experimental, as aves submetidas ao sistema de fracionamento de cálcio 1:3 apresentaram ovos 
Tabela 17 - Valores de percentagem de casca dos ovos (\%) por período do dia (total, manhã e tarde) de poedeiras alimentadas com diferentes fracionamentos de cálcio e granulometrias de calcário

\begin{tabular}{|c|c|c|c|c|c|c|c|c|}
\hline \multirow[t]{2}{*}{ Característica } & \multirow[t]{2}{*}{ Período } & \multicolumn{3}{|c|}{ Fracionamento de cálcio ( $\mathrm{g}$ manhã : g tarde) } & \multicolumn{3}{|c|}{ Granulometria de calcário $^{1}$} & \multirow[t]{2}{*}{ CV (\%) } \\
\hline & & $2: 2$ & $1: 3$ & $3: 1$ & Mista & Grossa & Fina & \\
\hline Total do dia & $\begin{array}{l}1 \\
2 \\
3 \\
4 \\
\text { Geral }\end{array}$ & $\begin{array}{c}10,51 \\
9,72 \\
9,65 \\
9,42 \\
9,82\end{array}$ & $\begin{array}{c}10,65 \\
9,64 \\
9,58 \\
9,61 \\
9,87\end{array}$ & $\begin{array}{c}10,34 \\
9,62 \\
9,41 \\
9,38 \\
9,70\end{array}$ & $\begin{array}{c}10,42 \\
9,78 \\
9,61 \\
9,44 \\
9,81\end{array}$ & $\begin{array}{c}10,67 \\
9,63 \\
9,66 \\
9,60 \\
9,89\end{array}$ & $\begin{array}{c}10,43 \\
9,57 \\
9,36 \\
9,37 \\
9,68\end{array}$ & $\begin{array}{l}8,44 \\
5,31 \\
4,20 \\
4,06 \\
3,27\end{array}$ \\
\hline Período da manhã & $\begin{array}{l}1 \\
2 \\
3 \\
4 \\
\text { Geral }\end{array}$ & $\begin{array}{c}10,32 \\
9,74 \\
9,41 \\
9,27 \mathrm{~b} \\
9,68\end{array}$ & $\begin{array}{c}10,83 \\
9,66 \\
9,27 \\
9,56 \text { a } \\
9,83\end{array}$ & $\begin{array}{c}10,65 \\
9,54 \\
9,20 \\
9,35 \mathrm{ab} \\
9,68\end{array}$ & $\begin{array}{c}10,62 \\
9,75 \\
9,34 \mathrm{ab} \\
9,34 \\
9,76 \\
\end{array}$ & $\begin{array}{c}10,67 \\
9,74 \\
9,47 \mathrm{a} \\
9,53 \\
9,85 \\
\end{array}$ & $\begin{array}{c}10,52 \\
9,45 \\
9,08 \mathrm{~b} \\
9,31 \\
9,59\end{array}$ & $\begin{array}{c}13,71 \\
4,23 \\
3,25 \\
3,41 \\
4,58 \\
\end{array}$ \\
\hline Período da tarde & $\begin{array}{l}1 \\
2 \\
3 \\
4 \\
\text { Geral }\end{array}$ & $\begin{array}{c}9,72 \\
9,95 \\
10,16 \\
10,71 \\
10,04\end{array}$ & $\begin{array}{c}10,00 \\
9,91 \\
9,90 \\
10,30 \\
9,94\end{array}$ & $\begin{array}{c}9,84 \\
9,84 \\
9,50 \\
10,24 \\
9,85\end{array}$ & $\begin{array}{c}9,86 \\
10,02 \\
10,10 \\
10,16 \\
10,02\end{array}$ & $\begin{array}{c}9,99 \\
9,97 \\
9,62 \\
10,79 \\
9,96\end{array}$ & $\begin{array}{c}9,71 \\
9,71 \\
9,83 \\
10,30 \\
9,86\end{array}$ & $\begin{array}{l}6,05 \\
6,50 \\
5,69 \\
6,38 \\
5,18\end{array}$ \\
\hline
\end{tabular}

1 Granulometria dos calcários (mm): Mista $=30 \%$ de calcário grosso e $70 \%$ de calcário fino; Grossa: entre 3,0 e 5,0 mm; Fina: inferior a 0,5 mm 
Tabela 18 - Valores de espessura de casca dos ovos $(\mathrm{mm})$ por período do dia (total, manhã e tarde) de poedeiras alimentadas com diferentes fracionamentos de cálcio e granulometrias de calcário

\begin{tabular}{|c|c|c|c|c|c|c|c|c|}
\hline \multirow[t]{2}{*}{ Característica } & \multirow[t]{2}{*}{ Período } & \multicolumn{3}{|c|}{ Fracionamento de cálcio (g manhã : g tarde) } & \multicolumn{3}{|c|}{ Granulometria de calcário $^{1}$} & \multirow[t]{2}{*}{ CV $(\%)$} \\
\hline & & $2: 2$ & $1: 3$ & $3: 1$ & Mista & Grossa & Fina & \\
\hline Total do dia & $\begin{array}{l}1 \\
2 \\
3 \\
4 \\
\text { Geral }\end{array}$ & $\begin{array}{c}0,41 \\
0,41 \text { a } \\
0,41 \\
0,42 \\
0,41 \\
\end{array}$ & $\begin{array}{c}0,41 \\
0,40 \mathrm{ab} \\
0,42 \\
0,40 \\
0,41\end{array}$ & $\begin{array}{c}0,41 \\
0,39 \mathrm{~b} \\
0,41 \\
0,41 \\
0,40 \\
\end{array}$ & $\begin{array}{l}0,41 \\
0,40 \\
0,41 \\
0,42 \\
0,41 \\
\end{array}$ & $\begin{array}{l}0,41 \\
0,40 \\
0,42 \\
0,42 \\
0,41 \\
\end{array}$ & $\begin{array}{l}0,41 \\
0,40 \\
0,41 \\
0,40 \\
0,40 \\
\end{array}$ & $\begin{array}{l}5,81 \\
4,11 \\
3,79 \\
8,16 \\
3,30\end{array}$ \\
\hline Período da manhã & $\begin{array}{l}1 \\
2 \\
3 \\
4 \\
\text { Geral }\end{array}$ & $\begin{array}{c}0,42 \text { a } \\
0,40 \text { a } \\
0,41 \\
0,40 \\
0,41 \text { a }\end{array}$ & $\begin{array}{c}0,41 \mathrm{ab} \\
0,39 \mathrm{ab} \\
0,42 \\
0,41 \\
0,40 \mathrm{ab}\end{array}$ & $\begin{array}{c}0,40 \mathrm{~b} \\
0,37 \mathrm{~b} \\
0,41 \\
0,41 \\
0,40 \mathrm{~b}\end{array}$ & $\begin{array}{l}0,41 \\
0,39 \\
0,41 \\
0,41 \\
0,41\end{array}$ & $\begin{array}{l}0,41 \\
0,39 \\
0,42 \\
0,41 \\
0,41\end{array}$ & $\begin{array}{l}0,40 \\
0,38 \\
0,41 \\
0,40 \\
0,40\end{array}$ & $\begin{array}{l}3,97 \\
3,03 \\
3,29 \\
4,08 \\
2,38\end{array}$ \\
\hline Período da tarde & $\begin{array}{l}1 \\
2 \\
3 \\
4 \\
\text { Geral }\end{array}$ & $\begin{array}{l}0,42 \\
0,42 \\
0,42 \\
0,43 \\
0,42\end{array}$ & $\begin{array}{l}0,42 \\
0,42 \\
0,42 \\
0,42 \\
0,41\end{array}$ & $\begin{array}{l}0,41 \\
0,41 \\
0,41 \\
0,41 \\
0,41\end{array}$ & $\begin{array}{l}0,42 \\
0,42 \\
0,42 \\
0,42 \\
0,42\end{array}$ & $\begin{array}{l}0,42 \\
0,42 \\
0,42 \\
0,42 \\
0,42\end{array}$ & $\begin{array}{l}0,42 \\
0,42 \\
0,41 \\
0,42 \\
0,41\end{array}$ & $\begin{array}{l}5,95 \\
6,97 \\
6,50 \\
4,79 \\
7,58\end{array}$ \\
\hline
\end{tabular}

Médias seguidas de letras diferentes em cada linha e em cada fator diferem entre si pelo teste de Tukey $(p<0,05)$

1 Granulometria dos calcários $(\mathrm{mm})$ : Mista $=30 \%$ de calcário grosso e $70 \%$ de calcário fino; Grossa: entre 3,0 e 5,0 mm; Fina: inferior a 0,5 mm 
Tabela 19 - Valores de densidade aparente dos ovos $\left(\mathrm{g} / \mathrm{mL} \mathrm{H}_{2} \mathrm{O}\right)$ por período do dia (total, manhã e tarde) de poedeiras alimentadas com diferentes fracionamentos de cálcio e granulometrias de calcário

\begin{tabular}{|c|c|c|c|c|c|c|c|c|}
\hline \multirow[t]{2}{*}{ Característica } & \multirow[t]{2}{*}{ Período } & \multicolumn{3}{|c|}{ Fracionamento de cálcio (g manhã : g tarde) } & \multicolumn{3}{|c|}{ Granulometria de calcário $^{1}$} & \multirow[t]{2}{*}{$\mathrm{CV}(\%)$} \\
\hline & & $2: 2$ & $1: 3$ & $3: 1$ & Mista & Grossa & Fina & \\
\hline Total do dia & $\begin{array}{l}1 \\
2 \\
3 \\
4 \\
\text { Geral }\end{array}$ & $\begin{array}{l}1,090 \\
1,090 \\
1,088 \\
1,089 \\
1,089 \\
\end{array}$ & $\begin{array}{l}1,090 \\
1,089 \\
1,089 \\
1,090 \\
1,090 \\
\end{array}$ & $\begin{array}{l}1,090 \\
1,089 \\
1,088 \\
1,088 \\
1,089 \\
\end{array}$ & $\begin{array}{c}1,090 \\
1,090 \\
1,088 \\
1,089 \\
1,089 \mathrm{ab}\end{array}$ & $\begin{array}{c}1,091 \\
1,090 \\
1,089 \\
1,089 \\
1,090 \mathrm{a}\end{array}$ & $\begin{array}{r}1,090 \\
1,088 \\
1,088 \\
1,088 \\
1,088 \text { b }\end{array}$ & $\begin{array}{l}0,20 \\
0,24 \\
0,19 \\
0,29 \\
0,15\end{array}$ \\
\hline Período da manhã & $\begin{array}{l}1 \\
2 \\
3 \\
4 \\
\text { Geral }\end{array}$ & $\begin{array}{c}1,090 \\
1,089 \\
1,086 \mathrm{~b} \\
1,088 \\
1,088\end{array}$ & $\begin{array}{c}1,089 \\
1,088 \\
1,089 \text { a } \\
1,089 \\
1,089\end{array}$ & $\begin{array}{c}1,090 \\
1,088 \\
1,087 \mathrm{ab} \\
1,088 \\
1,088\end{array}$ & $\begin{array}{c}1,090 \\
1,088 \mathrm{ab} \\
1,088 \\
1,088 \mathrm{~b} \\
1,089 \mathrm{a}\end{array}$ & $\begin{array}{c}1,090 \\
1,089 \mathrm{a} \\
1,088 \\
1,090 \mathrm{a} \\
1,089 \mathrm{a}\end{array}$ & $\begin{array}{c}1,089 \\
1,087 \mathrm{~b} \\
1,087 \\
1,087 \mathrm{~b} \\
1,087 \mathrm{~b}\end{array}$ & $\begin{array}{l}0,22 \\
0,22 \\
0,19 \\
0,19 \\
0,15\end{array}$ \\
\hline Período da tarde & $\begin{array}{l}1 \\
2 \\
3^{*} \\
4 \\
\text { Geral }\end{array}$ & $\begin{array}{l}1,091 \\
1,091 \\
1,093 \\
1,090 \\
1,091\end{array}$ & $\begin{array}{l}1,091 \\
1,091 \\
1,090 \\
1,092 \\
1,091\end{array}$ & $\begin{array}{l}1,091 \\
1,091 \\
1,089 \\
1,088 \\
1,090\end{array}$ & $\begin{array}{l}1,091 \\
1,092 \\
1,091 \\
1,092 \\
1,091\end{array}$ & $\begin{array}{l}1,092 \\
1,091 \\
1,091 \\
1,088 \\
1,091\end{array}$ & $\begin{array}{l}1,090 \\
1,090 \\
1,090 \\
1,090 \\
1,090\end{array}$ & $\begin{array}{l}0,34 \\
0,38 \\
0,37 \\
0,54 \\
0,25\end{array}$ \\
\hline
\end{tabular}

Médias seguidas de letras diferentes em cada linha e em cada fator diferem entre si pelo teste de Tukey $(p<0,05)$

1 Granulometria dos calcários $(\mathrm{mm})$ : Mista $=30 \%$ de calcário grosso e $70 \%$ de calcário fino; Grossa: entre 3,0 e 5,0 mm; Fina: inferior a 0,5 mm 
com maior percentual de casca em comparação às que foram alimentadas pelo sistema 2:2.

A espessura de casca também não foi influenciada pelos fatores estudados quando todo o período experimental foi considerado (Tabela 18). Porém, diferenças estatísticas $(P<0,05)$ foram observadas através da análise dos resultados por período experimental ou horário de coleta. Para as médias obtidas através da análise de todos os ovos coletados, durante o período experimental 2, o sistema de fracionamento de cálcio 3:1 resultou na produção de ovos com menor espessura de casca em comparação aos ovos de aves alimentadas pelo sistema 2:2. Além disso, foram observados resultados semelhantes quando a análise foi realizada considerando-se os ovos coletados no período da manhã. Este fato pôde ser observado durante os dois primeiros períodos experimentais, assim como quando a média total do período experimental foi considerada.

Para o parâmetro de densidade aparente dos ovos, também puderam ser observadas diferenças significativas e interações $(P<0,05)$ em períodos experimentais isolados (Tabela 19).

A análise de todos os ovos coletados demonstra que houve efeito significativo $(P<0,05)$ do fator granulometria do calcário sobre a densidade aparente dos ovos. Aves alimentadas apenas com calcário fino produziram ovos de menor densidade aparente quando comparados ao uso de calcário grosso $\left(1,088\right.$ e $\left.1,090 \mathrm{~g} / \mathrm{mL} \mathrm{H}_{2} \mathrm{O}\right)$. Quando foram considerados apenas os ovos coletados no período da manhã, repetiu-se a diferença entre o uso de 
calcário fino em relação às demais granulometrias (períodos experimentais 1,2 e geral).

Também, o fator fracionamento através do sistema 1:3 proporcionou ovos com maior densidade aparente em comparação ao sistema 2:2.

Para a análise dos ovos coletados no período vespertino observou-se uma interação $(P<0,05)$ cujo desdobramento é apresentado na Tabela 20 . A associação do calcário grosso com o sistema de fracionamento 3:1 resultou em ovos de menor densidade aparente $\left(1,085 \mathrm{~g} / \mathrm{mL}_{2} \mathrm{H}_{2} \mathrm{O}\right)$ quando comparado à combinação com o fracionamento $2: 2\left(1,095 \mathrm{~g} / \mathrm{mL} \mathrm{H}_{2} \mathrm{O}\right)$.

Tabela 20 - Desdobramento dos tratamentos referentes à característica densidade aparente $\left(\mathrm{g} / \mathrm{mL} \mathrm{H}_{2} \mathrm{O}\right)$ de ovos coletados à tarde de poedeiras alimentadas com diferentes fracionamentos de cálcio e granulometrias de calcário

\begin{tabular}{cccc}
\hline $\begin{array}{c}\text { Fracionamento de cálcio } \\
(\text { g manhã }: \text { g tarde })\end{array}$ & \multicolumn{3}{c}{ Granulometrias de calcário } \\
\cline { 2 - 4 } & \multicolumn{3}{c}{ Mensidade aparente - Período 3} \\
$2: 2$ & $1,090 \mathrm{Aa}$ & $1,095 \mathrm{Aa}$ & $1,093 \mathrm{Aa}$ \\
$1: 3$ & $1,092 \mathrm{Aa}$ & $1,093 \mathrm{Aab}$ & $1,085 \mathrm{Aa}$ \\
$3: 1$ & $1,093 \mathrm{Aa}$ & $1,085 \mathrm{Ab}$ & $1,091 \mathrm{Aa}$ \\
\hline
\end{tabular}

Médias seguidas de mesma letra maiúscula (minúscula) em cada linha (coluna) não diferem entre si pelo teste de Tukey $(p>0,05)$

Os resultados obtidos no presente estudo assemelham-se a outros obtidos anteriormente. Maior resistência da casca foi obtida através do oferecimento de $2,25 \%$ de cálcio no período da manhã e $4,75 \%$ de cálcio no período da tarde em estudo realizado por MAGGIONI et al. (1996). O resultado foi atribuído a um maior percentual e espessura de casca dos ovos produzidos por aves submetidas a este fracionamento. 
Os dados obtidos para a densidade aparente dos ovos, assemelhamse aos publicados por KESHAVARZ $\left(1998^{b}\right)$ porque também foi verificado redução na densidade aparente dos ovos quando maior quantidade de cálcio foi oferecida no período da manhã. Em matrizes pesadas e poedeiras, o oferecimento de cálcio no período da manhã resultou em ovos de menor qualidade externa em comparação ao de aves alimentadas no período da tarde (LENNARDS e ROLAND, 1981; FARMER et al., 1983; CASON e BRITTON, 1986; BRAKE, 1988).

Estudos preliminares realizados por LEESON e SUMMERS (1979 e 1980) e CHAH e MORAN (1985) demonstraram que as aves consomem maiores quantidades de cálcio no período da tarde quando submetidas ao sistema de cafeteria, em conjunto, também têm sido observadas melhoras significativas na qualidade de casca e melhora na eficiência de absorção de cálcio.

Por outro lado, em estudo mais recente realizado por WALDROUP e HELLWIG (2000), o sistema de fracionamento de cálcio não influenciou este parâmetro. Este estudo merece destaque por relacionar o fracionamento de cálcio ao fracionamento de fósforo, onde os melhores resultados de qualidade de casca foram obtidos após oferecer para as aves $0,82 \%$ de fósforo e 2,00\% de cálcio no período da manhã e 0,09\% de fósforo e 6,50\% de cálcio no período da tarde.

Para o fator granulometria também existem resultados semelhantes aos obtidos no presente estudo. GUINOTTE e NYS $\left(1991^{\text {b }}\right)$ estudaram diversas combinações entre origens e granulometrias de diversas fontes de 
cálcio. Através deste estudo observou-se que o uso de fontes de cálcio com granulometria inferior a $1,00 \mathrm{~mm}$ resultou em menor peso da casca e resistência da casca

A revisão de literatura realizada por ROLAND (1986) demonstra que o uso de fontes de cálcio de granulometria superior a 3,00 $\mathrm{mm}$ proporcionam qualidade de casca semelhante para fontes distintas (farinha de ostras e calcário). Quando se faz uso somente de fontes finas de cálcio os resultados obtidos para os parâmetros de qualidade de casca têm sido inferiores. À exemplo disto, através da incorporação de fontes de cálcio com granulometria superior a 3,00 mm, SCHEIDELER (1998) obteve maior densidade aparente dos ovos em comparação ao uso de fontes de cálcio com granulometria inferior a $0,50 \mathrm{~mm}$.

É importante salientar que a maior demanda de cálcio para deposição da casca ocorre durante o período noturno, iniciando em torno de 16 horas antes da postura do ovo (CLUNIES et al., 1993). Para atender a esta demanda, ocorrem algumas alterações fisiológicas, por exemplo, maior secreção de ácido clorídrico no proventrículo (SHIMADA, 1986), aumento na produção de proteína carreadora de cálcio (calbidina) e liberação de cálcio ósseo (ETCHES, 1995).

Analisando a ingestão de cálcio, cálcio sérico e excreção de cálcio, os maiores valores já haviam sido observados também durante o período noturno (ROLAND et al., 1972, PARSONS e COMBS, 1981; FARMER et al., 1983; CLUNIES e LEESON, 1995; CLUNIES et al., 1993). Sendo assim, justificam-se os melhores resultados obtidos para a qualidade externa dos 
ovos quando são utilizadas fontes de cálcio com granulometria superior a $3,00 \mathrm{~mm}$ para que fiquem retidas na moela e possam ser solubilizadas gradativamente durante o período de maior deposição da casca do ovo, fato este confirmado por RAO e ROLAND (1989 e 1990) e ZHANG e COON $\left(1997^{\mathrm{a}}\right)$

Foram esses estudos referentes à dinâmica do cálcio durante o processo de formação da casca do ovo que sustentaram, além desta linha de pesquisa relacionada à granulometria das fontes de cálcio, outras como a do fracionamento de cálcio (MAGGIONI et al., 1996; KESHAVARZ, $1998^{a}$ e 1998'; WALDROUP e HELLWIG, 2000), oferecimento de suplemento de cálcio no período da tarde (REIS et al., 1995) e complemento de luz durante o período noturno - "lanche da meia-noite" (HARMS et al., 1996)

As diferenças de qualidade externa dos ovos observadas para os diferentes horários de coleta foram descritas anteriormente por HESTER (1986). Outros fatores que podem estar relacionados à qualidade de casca são: diferenças entre variedades de aves, idade, fotoperíodo, conteúdo de cálcio e outros minerais, equilíbrio ácido-base (HAMILTON, 1981; ROLAND, 1982; CURTIS et al., 1985; KESHAVARZ e NAKAJIMA, 1993; NOVO et al., 1997; ITO, 1998).

Não têm sido encontradas diferenças para os parâmetros de integridade óssea havendo variação na ingestão diária de cálcio entre 2,00 e 4,50 g/ave/dia analisadas durante 6 semanas (CHENG e COON, 1990).

Em contraste aos resultados obtidos com poedeiras, para frangos de corte, os melhores resultados de ganho de peso e integridade óssea têm 
sido relatadas com o uso de calcário fino (McNAUGHTON, 1981 e GUINOTTE et al., 1991).

\subsection{Solubilidade dos calcários}

Os valores de solubilidade dos calcários utilizados (Tabela 21), determinados através da metodologia descrita por ZHANG e COON (1997), são semelhantes aos apresentadas por SCOTT (1991). Para o calcário fino são esperados percentuais de solubilidade variando entre 50 a $70 \%$. Para o calcário grosso e farinha de ostras a solubilidade esperada encontra-se entre 20 a $40 \%$, enquanto para a mistura de calcário grosso e fino a solubilidade esperada pode variar de 40 a $50 \%$. Estudos sobre a solubilidade da farinha de ostras indicam que sua maior solubilidade em relação ao calcário pode ser atribuída à maior porosidade da matéria (GUINOTTE e NYS, 1991).

A solubilidade obtida para o calcário grosso está próxima da sugerida por CHENG e COON (1990) para maior deposição de cálcio ósseo e densidade aparente dos ovos, 11 a 14\%. A solubilidade da mistura de calcários foi estimada a partir das solubilidades dos calcários grosso e fino mantendo-se a relação entre eles de 30:70. O valor obtido $(41,62 \%)$ aproximou-se do valor estimado $(41,25 \%)$.

O conhecimento da solubilidade dos calcários em separado pode nos auxiliar a avaliar a proporção ideal entre os diversos perfis das fontes de cálcio para melhor atendimento das exigências da ave durante o processo de formação da casca. 
Tabela 21 - Valores de solubilidade e concentração de cálcio de diferentes fontes de cálcio

\begin{tabular}{lcc}
\hline Tipo de calcário & Solubilidade (\%) & Cálcio (\%) \\
\hline Calcário Fino & 50,10 & 35,00 \\
Calcário Grosso & 20,50 & 36,00 \\
Misto (70\% Fino + 30\% Grosso) - obtido & 41,60 & 35,5 \\
Misto (70\% Fino + 30\% Grosso) - estimado & 41.25 & 35,3 \\
\hline
\end{tabular}




\section{CONCLUSÕES}

Nas condições de realização do presente estudo conclui-se:

A prática de fracionar o cálcio da dieta não influenciou negativamente as principais características de desempenho e qualidade interna dos ovos em todo o período experimental. No entanto, a qualidade externa dos ovos pode ser melhorada quando dietas com níveis mais elevados de cálcio são oferecidas no período da tarde.

Não houve alteração nas principais características de desempenho e qualidade interna dos ovos através do uso de calcários com diversas granulometrias. Porém, apenas a utilização de fontes finas de cálcio pode ser prejudicial para a qualidade externa dos ovos.

Estudos relacionados ao fracionamento de outros nutrientes, como energia, proteína e fósforo bem como suas combinações poderão ser realizados. $\mathrm{O}$ uso de poedeiras comerciais marrons e matrizes de poedeiras nestes estudos também deve ser considerado, pois não têm sido relatados estudos com outras aves que não sejam poedeiras comerciais brancas. 


\section{REFERÊNCIAS BIBLIOGRÁFICAS}

ADAMS, C.J.; BELL D.D. A model relating egg weight and distribution to age of hen and season. J.Appl. Poult. Sci., v. 7, p. 35-44, 1998.

BELYANIN, C.G. A need for research in calcium and phosphorus. World's Poult. Misset, p. 29-31, jun. 1987.

BRAKE, J. Relationship of time of feeding and strain to egg shell quality and hatchability in broiler breeders. Poult. Sci., v. 67, p. 538-543, 1988.

BRISTER, R.D.; LINTON, S.S.; CREGER, C.R. Effects of dietary calcium sources and particle size on laying hen performance. Poult. Sci., v.60, p.2648-2654, 1981.

CASON, J.A.; BRITTON, W.M. Effect of short-term feed deprivation on shell quality in laying hens. Poult. Sci., v. 59, p. 885-887, 1986.

CHAH, C.C.; MORAN Jr., E.T. Egg characteristics of high performance hens at the end of lay when given cafeteria access to energy, protein and calcium. Poult. Sci., v. 64, p. 1696-1712, 1985.

CHENG T.K.; COON, C.N. Effect on layer performance and shell quality of switching limestones with different solubilities. Poult. Sci., v. 69, p. 2199$2203,1990^{\mathrm{a}}$.

CHENG, T.K.; COON, C.N. Comparison of various In vitro methods for the determination of limestone solubility. Poult. Sci., v. 69, p. 2204-2208, $1990^{\mathrm{b}}$.

CHENG, T.K.; COON, C.N. Effect of calcium source, particle size, limestone solubility in vitro and calcium level on layer bone status and performance, Poult. Sci., v. 69, p. 2214-2219, 1990'. 
CLASSEN, H.L.; SCOTT, T.A. Self selection of calcium during the rearing and early laying periods of white Leghorn pullets. Poult. Sci., v. 61, p. 20652074, 1982.

CLUNIES, M.; EMSLIE, J.; LEESON, S. Effect of dietary calcium level on medullary bone calcium reserves and shell weight of Leghorn hens. Poult. Sci., v.71, p.1348-1356, 1992.

CLUNIES, M.; ETCHES, R.J.; FAIR, C.; LEESON, S. Blood, intestinal and skeletal calcium dynamics during egg formation. Can. J. Ani. Sci., v. 73, p. 517-532, 1993.

CLUNIES, M.; LEESON, S. Effect of dietary calcium level on plasma proteins and calcium flux occurring during a $24 \mathrm{~h}$ ovulatory cycle. Can. J. Ani. Sci, v. 75, p. 439-444, 1995.

COLE, D.J.; HARESIGN, W. Eggshell formation and quality. In: Recent developments in poultry nutrition. Nottingham School of Agriculture, v.1, p. 261-275, 1986.

ELAROUSSI, M.A.; FORTE, L.R.; EBER, S.L.; BIELLIER, H.V. Calcium homeostasis in the laying hen - age and dietary calcium effects. Poult. Sci., v. 73, p. 1581-1589, 1994.

ESTAT 2.0 Sistema de análise estatística. Jaboticabal: Polo Computacional Departamento de Ciências Exatas - UNESP; 1992.

ETCHES, R.J. Reproduction in poultry. CAB International, 1995. 398 p.

FARMER, M.; ROLAND, D.A.; CLARK, A.J. Influence of dietary calcium on bone calcium utilization. Poult. Sci., v. 65, p. 337-344, $1986^{a}$.

FARMER, M.; ROLAND, D.A. Influence of dietary ingredients on calcium utilization in the laying hens. Poult. Sci., v. 65 , p. 345-351, $1986^{\mathrm{b}}$.

FARMER, M.; ROLAND, D.A.; BRAKE, J.; ECKMAN, M.K. Calcium metabolism in broiler breeder hens -1 . Calcium status of the digestive tract of broiler breeders throughout a 24 hour period. Poult. Sci., v.62, p.459-464, 1983. 
FARMER, M.; ROLAND, D.A.; CLARK, A.J. Influence of time of calcium intake on bone and dietary calcium utilization. Poult. Sci., v. 65, p. 555-558, 1986.

GUINOTTE, F.; NYS, Y. The effects of a particulate calcium source in broiler breeder rens upon their egg quality, reproductive traits, bone reserves, chick weight and tibia strenght characteristics. Archiv fur Geflugelkunde, v. 55, p. $170-175,1991^{\mathrm{a}}$.

GUINOTTE, F.; NYS, Y. Effects of particle size and origin of calcium sources on eggshell quality and bone mineralization in laying hens. Poult. Sci., v. 70, p. $583-592,1991^{\mathrm{b}}$.

GUINOTTE, F.; NYS, Y.; MONREDON, F. The effects of particle size and origin of calcium carbonate on performance and ossification characteristics in broiler chicks. Poult. Sci., v. 70, p. 1908-1920, 1991.

HAMILTON, R.M.G. The effects of strain, age, time after oviposition and egg specific gravity on acid-base balance in white Leghorn hens. Poult. Sci., v. 60, p. 1944-1950, 1981.

HARMS, R.H. The influence of nutrition on egg shell quality. Feedstuffs, $p$. 25-27, maio 1982.

HARMS, R.H. Specific gravity of eggs and eggshell weight from commercial layers and broiler breeders in relation to time of oviposition. Poult. Sci., v. 70, p. $1099-1104,1991^{\text {a }}$.

HARMS, R.H. The influence of changing time of feeding on performance of broiler breeder hens. Poult. Sci., v. 70, p. 1695-1698, 1991 ${ }^{\mathrm{b}}$.

HARMS, R.H.; DOUGLAS, C.R.; SLOAN, D.R. Midnight feeding of commercial laying hens can improve eggshell quality. J. Appl. Poult. Res., v. 5 , p. 1-5, 1996.

HESTER, P.Y. Shell mineral content of morning versus afternoon eggs.

Poult. Sci., v. 65, p. 1821-1823, 1986.

HOLCOMBE, D.J.; ROLAND, D.A.; HARMS, R.H. The ability to adjust calcium intake when given a choice of diets containing two levels of calcium.

Poult. Sci., v. 54, p. 552-561, 1975. 
HOLCOMBE, D.J.; ROLAND, D.A.; HARMS, R.H. The effect of increased dietary calcium on hens chosen for their ability to produce eggs with high and low specific gravity. Poult. Sci., v. 56, p. 90-93, 1977.

HURWITZ, S.; BAR, A. Intestinal calcium absorption in the laying fowl and its importance in calcium homeostasis. Am. J. Clin. Nut., v. 22, p. 391-395, 1969.

IEDA, T.; SAITO, N.; ONO, T.; SHIMADA, K. Effects of presence of na egg and calcium deposition in the Shell gland on levels of messenger ribonucleic acid of CaBP-D $(28 \mathrm{k})$ and on vitamin D3 receptor in the Shell gland of the laying hens. Gen. Comp. Endocrinol., v. 99, p. 145-151, 1995.

ISA-BABCOCK. Manual de manejo-BABCOCK B300N, 2000. 25 p.

ITO, R.I. Aspectos nutricionais relacionados à qualidade de casca de ovos. In: SIMPÓSIO TÉCNICO DE PRODUÇÃO DE OVOS. Anais... APA ASSOCIAÇÃO PAULISTA DE AVICULTURA, 1998. p. 119-138.

JOSHUA, I.G.;MUELLER, W.J. The development of a specific appetite for calcium in growing broiler chickens. Br. Poult. Sci., v. 20, p. 481-490, 1979.

KESHAVARZ, K. The effect of dietary levels of calcium and phosphorus on performance and retention of these nutrients by laying hens. Poult. Sci., v.65, p.114-121, 1986.

KESHAVARZ, K. Investigation on the possibility of reducing protein, phosphorus and calcium requirements of laying hens by manipulation of time of access to these nutrients. Poult. Sci., v. 77, p. 1320-1332, $1998^{a}$.

KESHAVARZ, K. Further investigations on the effect of dietary manipulation of protein, phosphorus and calcium for reducing their dietary daily requirements for laying hens. Poult. Sci., v. 77, p. 1333-1346, $1998^{\mathrm{b}}$.

KESHAVARZ, K.; NAKAJIMA, S. Re-evaluation of calcium and phosphorus requirements of laying hens for optimun performance and eggshell quality.

Poult. Sci., v.72, p.144-153, 1993.

KESHAVARZ, K.; SCOTT, M.L.; BLANCHARD, J. The effect of solubility and particle size of calcium sources on shell quality and bone mineralization. $\mathbf{J}$.

Appl. Poult. Res., v. 2, p. 259-267, 1993. 
LEESON, S.; SUMMERS, J.D. Dietary self selection by layers. Poult. Sci., v. 58 , p. 646-651, 1979.

LEESON, S.; SUMMERS, J.D. Effect of early light treatment and diet self selection on laying performance. Poult. Sci., v. 59, p. 11-15, 1980.

LENNARDS, R.; ROLAND, D.A.; McGUIRE, J.A. The relationship of serum calcium to shell weight and the other criteria in hens laying a low or high incidence of shell less eggs. Poult.Sci., v. 60, p. 2501-2505, 1981.

MAGGIONI, R.; RUTZ, F.; ROLL, V.F.B.; RINALDI, M.M.; NAMAZU, L. Efeito do horário de fracionamento de dietas contendo diferentes níveis de cálcio sobre o desempenho produtivo e qualidade de casca em poedeiras semipesadas no verão. In: REUNIÃO ANUAL DA SOCIEDADE BRASILEIRA DE ZOOTECNIA, 33. 1996. Fortaleza. Anais... Fortaleza: SBZ, 1996. v. 4, p. 47-49.

MARCH, B.E.; AMIN, M. Dietary limestone versus extra dietary oyster shell as calcium supplements to different layer diets. Poult. Sci., v. 60, p. 591597, 1981.

McNAUGHTON, J.L. Effect of calcium carbonate particle size on the available phosphorus requirements of broiler chicks. Poult. Sci., v. 60, p. 197-203, 1981.

MILES, R. Fatores nutricionais relacionados à qualidade da casca dos ovos. In: SIMPÓSIO GOIANO DE AVICULTURA, 4., 2000. Goiânia. Anais... Goiânia: Associação Goiânia de Avicultura, 2000. p. 195-173.

MORENG, R.E.; AVENS, J.S. Ciência e produção de aves. São Paulo: Roca, 1990. 380 p.

MUIRHEAD, S. Poor bone structure in laying hens directly related to calcium demand. Feedstuffs, p. 12, maio 1991.

NAKAJIMA, S.; NAKAGAWA, J.; OKUMURA, J. Effect of limestone particle size on laying hens performance. Jap. J. Ani. Sci., v.32, p.274-282, 1995.

NESHEIN, M.C.; AUSTIC, R.E.; CARD, L.E. Poultry production. 12. ed. Lea \& Febinger, 1979. 399 p. 
NIR, I.; NITSAN, Z.; DUNNINGTON, E.A.; SIEGEL, P.B. Aspects of food intake restriction in young domestic fowl: metabolic and genetic considerations. World's Poult. Sci. J., v. 52, p. 251-266, 1996.

NORDSTROM, J.O. Limited access to feed during egg formation and the shell quality of eggs laid in the afternoon. Poult. Sci., v. 59, p. 2749-2753, 1980.

NOVO; R.P.; GAMA, L.T.; SOARES, M.C. Effects of oviposition time, hen age and extra dietary calcium on egg characteristics and hatchability. J. Appl. Poult. Res., v. 6, p. 335-343, 1997.

PARSONS, A.H.; COMBS Jr., G.F. Blood ionized calcium cycles in the chicken. Poult. Sci., v. 60, p. 1520-1524, 1981.

REICHMANN, K.G.; CONNOR, J.K. The effects of meal feeding of calcium, protein and energy on production and calcium status of laying hens. Br. Poult. Sci., v. 20, p. 445-452, 1979.

REIS, L.H.; FEIO, P.; GAMA; L.T.; SOARES, M.C. Extra dietary calcium supplement and broiler breeders. J. Appl. Poult. Res., v. 4, p. 276-282, 1995.

ROLAND, D.A. Egg shell quality: oyster shell versus limestone and the importance of particle size or solubility of calcium source. World's Poult. Sci. J., v. 42, p. 166-171, 1986.

ROLAND, D.A. Egg shell problems: estimates of incidence and economic impact. Poult. Sci., v. 67, p. 1801-1803, 1988.

SHIMADA, K. Gizzard motility in relation to oviposition in the chicken. Poult. Sci., v. 65, p.1796-1800, 1986.

ROLAND, D.A.; SLOAN, D.R.; HARMS, R.H. Calcium metabolism in the laying hen - patterns of calcium intake, serum calcium and fecal calcium, Poult. Sci., v. 51, p. 782-787, 1972.

ROLAND, D.A.; SLOAN, D.R.; HARMS, R.H. Calcium metabolism in the laying hen - shell quality in relation to time of oviposition. Poult. Sci., v. 52, p. 506-510, 1973. 
SCHEIDELER, S.E. Eggshell calcium effects o egg quality and calcium digestibility in first or third cycle laying hens. J. Appl. Poult. Res., v. 7, p. 69-74, 1998.

SCOTT, M. How can calcium be supplied to high producing hens?.

Feedstuffs, v. 63, p. 16-18, maio 1991.

STADELMAN, W.J.; PRATT, D.E. Factors influencing composition of the hen egg. World's Poul. Sci. J., V.45, P.247-260, 1989.

SWENSON, M.J.; REECE, W.O. Dukes: fisiologia dos animais domésticos. 11. ed. Rio de Janeiro: Guanabara Koogan, 1996. 856 p.

WALDROUP, P.W.; HELLWIG, H.M. The potencial value of morning and afternoon feeds for laying hens. J. Appl. Poult. Res., v. 9, p. 98-110, 2000.

WASHBURN, K.W. Incidence, cause and prevention of egg shell breakage in commercial production. Poult. Sci., v. 61, p. 2005-2012.

WILLIAMS, K.C. Some factors affecting albumen quality with particular reference to Haugh unit score. World's Poult. Sci. J., v. 48, p. 5-16, 1992.

ZHANG, B.; COON, C.N. The relationship of calcium intake, source size, solubility in vitro and in vivo and gizzard limestone retention in laying hens. Poult. Sci., v. 76, p. 1702-1706, $1997^{\mathrm{a}}$.

ZHANG, B.; COON, C.N. Improved In vitro methods for determining limestone and oyster shell solubility. J. Appl. Poult. Res., v. 6, p. 94-99, $1997^{\mathrm{b}}$. 